\title{
CAMA
}

Centre for Applied Macroeconomic Analysis

\section{Does Home Production Drive Structural Transformation?}

\section{CAMA Working Paper 19/2016 April 2016}

Alessio Moro

University of Cagliari

Solmaz Moslehi

Monash University

\section{Satoshi Tanaka}

University of Queensland and

Centre for Applied Macroeconomic Analysis, ANU

\section{Abstract}

Using new home production data for the U.S., we estimate a model of structural transformation with a home production sector, allowing for both non-homotheticity of preferences and differential productivity growth in each sector. We report two main findings. First, the estimation results show that home services have a lower income elasticity than market services. Second, the slowdown in home labor productivity, started in the late 70s, is a key determinant of the rise of market services. Our counterfactual experiment shows that, without the slowdown, the share of market services would be lower by $5.8 \%$ in 2010 . 


\section{Keywords}

Structural Change, Home Production, Services Sector.

\section{JEL Classification}

E20, E21, L16

\section{Address for correspondence:}

(E) cama.admin@anu.edu.au

\section{ISSN 2206-0332}

The Centre for Applied Macroeconomic Analysis in the Crawford School of Public Policy has been established to build strong links between professional macroeconomists. It provides a forum for quality macroeconomic research and discussion of policy issues between academia, government and the private sector.

The Crawford School of Public Policy is the Australian National University's public policy school, serving and influencing Australia, Asia and the Pacific through advanced policy research, graduate and executive education, and policy impact. 


\title{
Does Home Production
}

\section{Drive Structural Transformation?*}

\author{
Alessio Moro ${ }^{\dagger}$ \\ University of Cagliari
}

\author{
Solmaz Moslehi ${ }^{\ddagger}$ \\ Monash University
}

Satoshi Tanaka ${ }^{\S}$

University of Queensland

CAMA

April 7, 2016

\begin{abstract}
Using new home production data for the U.S., we estimate a model of structural transformation with a home production sector, allowing for both non-homotheticity of preferences and differential productivity growth in each sector. We report two main findings. First, the estimation results show that home services have a lower income elasticity than market services. Second, the slowdown in home labor productivity, started in the late 70s, is a key determinant of the rise of market services. Our counterfactual experiment shows that, without the slowdown, the share of market services would be lower by $5.8 \%$ in 2010 .
\end{abstract}

JEL Classification: E20, E21, L16.

Keywords: Structural Change, Home Production, Services Sector.

*We thank Benjamin Bridgman for providing the home production data for the U.S. We also thank Timo Boppart, Fabio Cerina, Horag Choi, Begoña Domínguez, Chris Edmond, Miguel León-Ledesma, Sephorah Mangin, Rachel Ngai, Michelle Rendall, Akos Valentinyi, Yuichiro Waki, and other seminar participants at Carlos III, Indiana University, Kansas City Fed, IMF, University of Melbourne, Monash University, University of Queensland, University of Tokyo, Keio University, Kyoto University, Hitotsubashi University, University of Warwick, Society for Economic Dynamics (Warsaw), Conference on Urbanization, Structural Change, and Employment (Hong Kong), Midwest Macro Meetings Fall 2015 (Rochester), Public Economic Theory (Luxembourg), and Workshop of Australasian Macroeconomics Society (Sydney) for their helpful comments and suggestions. The usual disclaimers apply.

${ }^{\dagger}$ Contact: amoro@unica.it.

$\ddagger$ Contact: solmaz.moslehi@monash.edu.au.

$\S$ Contact: s.tanaka@uq.edu.au. 


\section{Introduction}

Since the early 1990s, a number of studies have incorporated household home production in a neoclassical framework in order to explain several macroeconomic phenomena. ${ }^{1}$ Structural transformation is one of the fields in which researchers have recently been discussing the role of home production. ${ }^{2}$ While previous studies in this field have successfully derived rich implications by modeling home production, empirical works that assess the model's ability to explain the data have been limited. Therefore, an important question to be addressed in this literature is whether a structural transformation model with a home production sector is able to account for the actual home production data.

In this paper, we propose and estimate a model of structural transformation with a home production sector that can account for the movements of the home and market sector shares in extended total consumption in the U.S. ${ }^{3}$ In order to construct the home production data for the estimation, we follow the income approach recently developed in the literature, and compute the value added of home production from its input factors and their prices. ${ }^{4} \mathrm{We}$ then use the estimated model to study the role of a home production sector in the process of structural transformation. In particular, we run a counter-factual experiment to quantify the effects of the slowdown in home labor productivity growth in the U.S. after the late 1970s, which is documented in Bridgman (2013).

Our framework is based on a multi-sector growth model in which structural transformation is generated through non-homothetic preferences and differential productivity growth across sectors, as in Buera and Kaboski (2009). We extend this model to include a home production sector operated by the household. Since the inter-temporal and the intra-temporal problems can be solved independently in this class of growth models with structural transformation, we can re-write the latter as a static, consumption choice problem of the household, which depends on the prices for the three market goods, the implicit price for home produced services, and the extended total consumption. This last version of the model allows us to estimate the implied share equations, using the home production data together with the value added consumption data for the market sectors.

In the estimation, we explore different household preferences specifications. In particular,

\footnotetext{
${ }^{1}$ These studies include issues on business cycles (Benhabib, Rogerson, and Wright (1991); Greenwood and Hercowitz (1991)), life-cycle labor supply decisions (Ríos-Rull (1993)), and fiscal policy (McGrattan, Rogerson, and Wright (1997)), among others.

${ }^{2}$ The structural transformation literature started discussing home production following the two seminal papers, Rogerson (2008) and Ngai and Pissarides (2008).

${ }^{3}$ We define extended total consumption as the value of market consumption plus the value added of home production.

${ }^{4}$ Our income approach is similar to those in Landefeld, Fraumeni, and Vojtech (2009) and Bridgman (2013).
} 
Figure 1 - Home and Market Sector Shares (Left) and Home Labor Productivity (Right)
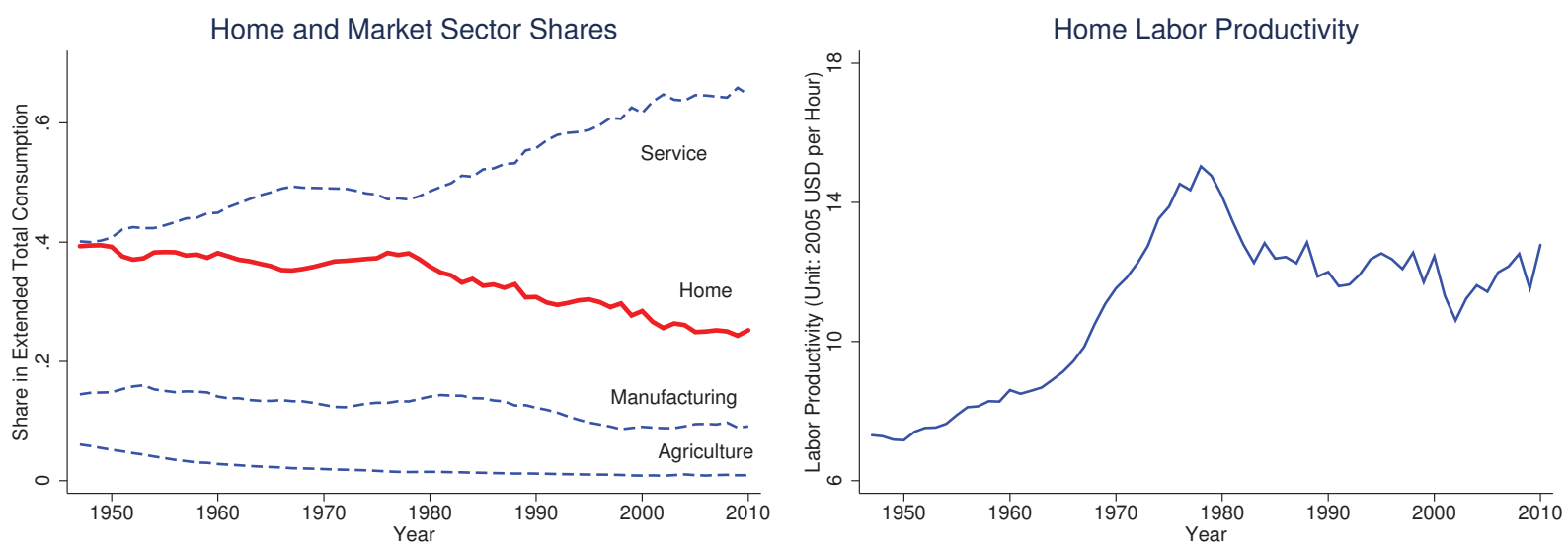

Note: The consumption value added of the market sectors is calculated based on the data of Herrendorf, Rogerson, and Valentinyi (2013). The consumption value added of the home sector is calculated by using the income approach similar to Bridgman (2013). The home labor productivity is obtained by deflating the value added of home production with the price index for the home sector and then dividing it by hours worked at home. The details of the data used here are discussed in Section 4.

we allow for different income elasticities of home and market services in the household consumption demand, something that has not been considered in the previous literature. ${ }^{5}$ This is motivated by the empirical evidence documented in Eichengreen and Gupta (2013), which suggests that market services with a home counterpart could have a different income elasticity from the other services. In our results, it turns out that this feature of the model is crucial to account for the data.

We highlight two main results. First, we find that home services have a lower income elasticity than market services. The estimation results indicate that, if the income elasticities are the same between market and home services, the model cannot generate the secular decline of the home service share since the late 1940s (see the left panel in Figure 1). This result contrasts with previous studies in the literature, which explain the movement of market and home service shares only through differences in the rates of technological progress across sectors. ${ }^{6}$ Our estimates suggest that the changes in technologies are not enough to account for the movement of the home and market shares observed in the data.

The second result is obtained by running a counter-factual experiment, in which we let home labor productivity grow after 1978 at the same average pace before the slowdown (see the right panel in Figure 1). We find that in the counter-factual the share of market

\footnotetext{
${ }^{5} \mathrm{~A}$ common assumption in previous works is to assume the same income elasticity for home and market services. See for instance Rogerson (2008), Ngai and Petrongolo (2013) and Rendall (2015).

${ }^{6}$ See Ngai and Pissarides (2008) and Buera and Kaboski (2012b) for example.
} 
services in the total consumption expenditure is 0.86 in 2010, compared to 0.81 without the slowdown, which shows a $5.8 \%$ decrease. That is, if there were no slowdown in home labor productivity, the extent of structural change would be considerably lower than the actual data indicates. This experiment therefore suggests that the home production sector can have quantitatively important implications for the structural change observed in market sectors.

Our paper relates to the literature, started by Rogerson (2008) and Ngai and Pissarides (2008), that considers home production as a key determinant in the process of structural transformation. More recent studies in this literature include Buera and Kaboski (2012a), who focus on differences in skill intensities between home and market, Buera and Kaboski (2012b), who model differences in production scale between home and market, Ngai and Petrongolo (2013), who study the rise of female labor force participation in the U.S., and Rendall (2015), who analyzes the implications of the difference in the tax system for female labor force participation between the U.S. and Germany. As emphasized above, while these studies have derived rich implications of structural transformation models with a home production sector, they do not estimate these models using actual home production data.

There are two recent contributions which estimate a model of structural transformation without a home production sector using the U.S. data. Buera and Kaboski (2009) estimate a three-sector model using the U.S. data in a general equilibrium framework. Herrendorf, Rogerson, and Valentinyi (2013), on the other hand, consider a partial equilibrium setup, and estimate a three-sector model using final consumption expenditure and consumption value-added data since 1947. Our methodology is close to that of Herrendorf, Rogerson, and Valentinyi (2013). However, we consider a structural transformation model with a home production sector, and estimate the model using the value added of home production together with consumption value added data for the market sectors.

Finally, our paper is also related to the literature which has developed the income approach to impute the value of non-market activities from input factors and their market prices. This idea goes back to as far as Kendrick (1979). In recent years, researchers at the BEA have further developed this approach to construct their Satellite Account for Household Production (Landefeld and McCulla (2000); Landefeld, Fraumeni, and Vojtech (2009); Bridgman, Dugan, Lal, Osborne, and Villones (2012); Bridgman (2013)). This paper's strategy to construct the home value added closely follows these works.

The reminder of the paper is as follows. Section 2 presents the model; Section 3 discusses the estimation procedure; Section 4 explains the data; Section 5 reports the estimation results, while Section 6 runs the counter-factual experiment. In Section 7, we consider an extension by disaggregating the service sector. In Section 8 , we discuss the implications of the model for hours worked. In Section 9, we conclude. 


\section{Model}

This section presents a model of structural transformation with a home production sector.

\subsection{Setup}

Time is discrete. There is a representative household, whose objective is to maximize her utility. There are five types of goods produced in this economy: four consumption goods (agriculture, manufacturing, market services, and home services) and one investment good. The household's preferences is given by

$$
u=\sum_{t=0}^{\infty} \beta^{t} \ln C_{t},
$$

where $\beta$ is the subjective discount factor. The composite consumption index $C_{t}$ is defined as

$$
C_{t}=\left(\sum_{i=a, m, s}\left(\omega^{i}\right)^{\frac{1}{\sigma}}\left(c_{t}^{i}+\bar{c}^{i}\right)^{\frac{\sigma-1}{\sigma}}\right)^{\frac{\sigma}{\sigma-1}}
$$

where $c_{t}^{i}$ denotes consumption of good $i \in\{a, m, s\}$. In (1), the parameter $\omega^{i}$ determines the weight on each good in the household's preferences; the parameter $\bar{c}^{i}$ controls nonhomotheticity in preferences; and the parameter $\sigma$ governs the elasticity of substitution among the three goods. Service consumption is a composite of market services, $c_{t}^{s m}$, and home produced services, $c_{t}^{s h}$, as

$$
c_{t}^{s}=\left[\psi\left(c_{t}^{s m}\right)^{\frac{\gamma-1}{\gamma}}+(1-\psi)\left(c_{t}^{s h}+\bar{c}^{s h}\right)^{\frac{\gamma-1}{\gamma}}\right]^{\frac{\gamma}{\gamma-1}} .
$$

In (2), the parameter $\gamma$ governs the elasticity of substitution between market and home services and $\psi$ is the share parameter in the service aggregator. Note that we allow for a different income elasticity between market and home services through the parameter $\bar{c}^{s h}$. We provide a discussion of this parameter in Section 2.4 and in the estimation section.

In our setup, for each period, the household is endowed with $\bar{l}=1$ unit of labor that she splits into working time in the market, $l_{t}^{m k}$, paid at wage $w_{t}$ and working time at home, $l_{t}^{s h}$. Also, the household holds the capital stock $k_{t}$ in the economy, and decides how much to rent in the market, $k_{t}^{m k}$, at rate $r_{t}$, and how much to use in home production, $k_{t}^{s h}$. Then, the household's constraints are given by

$$
p_{t}^{a} c_{t}^{a}+p_{t}^{m} c_{t}^{m}+p_{t}^{s m} c_{t}^{s m}+k_{t+1}^{m k}-(1-\delta) k_{t}^{m k}+k_{t+1}^{s h}-(1-\delta) k_{t}^{s h}=r_{t} k_{t}^{m k}+w_{t} l_{t}^{m k}
$$




$$
l_{t}^{m k}+l_{t}^{s h}=\bar{l},
$$

where $p_{t}^{j}$ is the price of good $j \in\{a, m, s m\}$ and $\delta$ is the depreciation rate. We normalize the price of the investment goods to be equal to one. The total amount of capital is defined as

$$
k_{t} \equiv k_{t}^{m k}+k_{t}^{s h}
$$

The household produces home services through the following technology,

$$
c_{t}^{s h}=A_{t}^{s h}\left(k_{t}^{s h}\right)^{\alpha}\left(l_{t}^{s h}\right)^{1-\alpha} .
$$

On the market production side, there is a perfectly competitive firm in each market sector $j \in\{a, m, s m\}$ with technology,

$$
Y_{t}^{j}=A_{t}^{j}\left(K_{t}^{j}\right)^{\alpha}\left(L_{t}^{j}\right)^{1-\alpha}
$$

Finally, there is also a perfectly competitive firm operating in the investment good sector with technology,

$$
Y_{t}^{x}=A_{t}^{x}\left(K_{t}^{x}\right)^{\alpha}\left(L_{t}^{x}\right)^{1-\alpha}
$$

\subsection{Household's Problem}

Next, we re-write the previous setup by treating the home production sector as being operated by a perfectly competitive firm. This allows us to consider the home production sector as an additional market sector, which helps us to simplify the problem. Assuming perfect competition in the home sector, we can define an implicit price index for the home good as

$$
p_{t}^{s h} \equiv \frac{r_{t}^{\alpha} w_{t}^{1-\alpha}}{A_{t}^{s h} \alpha^{\alpha}(1-\alpha)^{1-\alpha}} .
$$

Using the above price, we can show that

$$
p_{t}^{s h} c_{t}^{s h}=w_{t} l_{t}^{s h}+r_{t} k_{t}^{s h}
$$

We now add up (5) to the budget constraint of the household, (3), and obtain

$$
p_{t}^{a} c_{t}^{a}+p_{t}^{m} c_{t}^{m}+p_{t}^{s m} c_{t}^{s m}+p_{t}^{s h} c_{t}^{s h}+k_{t+1}-(1-\delta) k_{t}=r_{t} k_{t}+w_{t} \bar{l} .
$$


Thus, we can rewrite the household problem as

$$
\max \sum_{t=0}^{\infty} \beta^{t} \ln C_{t}
$$

subject to

$$
\begin{gathered}
C_{t}=\left(\sum_{i=a, m, s}\left(\omega^{i}\right)^{\frac{1}{\sigma}}\left(c_{t}^{i}+\bar{c}^{i}\right)^{\frac{\sigma-1}{\sigma}}\right)^{\frac{\sigma}{\sigma-1}}, \\
c_{t}^{s}=\left[\psi\left(c_{t}^{s m}\right)^{\frac{\gamma-1}{\gamma}}+(1-\psi)\left(c_{t}^{s h}+\bar{c}^{s h}\right)^{\frac{\gamma-1}{\gamma}}\right]^{\frac{\gamma}{\gamma-1}}, \\
p_{t}^{a} c_{t}^{a}+p_{t}^{m} c_{t}^{m}+p_{t}^{s m} c_{t}^{s m}+p_{t}^{s h} c_{t}^{s h}+k_{t+1}-(1-\delta) k_{t}=r_{t} k_{t}+w_{t} \bar{l} .
\end{gathered}
$$

Given the definition of the implicit price for home services (4), it is straight-forward to show that problem (P1) is equivalent to the original setup in Section 2.1.

\subsection{Separating Inter- and Intra-Temporal Problems}

As the final step toward the estimation, we show that the household's problem (P1) can be decomposed into the following two problems. $^{7}$

1. Inter-Temporal Problem: The household solves:

$$
\max _{\left\{C_{t}, k_{t+1}\right\}} \sum_{t=0}^{\infty} \beta^{t} \ln C_{t}
$$

subject to

$$
P_{t} C_{t}+k_{t+1}-(1-\delta) k_{t}=r_{t} k_{t}+w_{t} \bar{l}+p_{t}^{s h} \bar{c}^{s h}+\sum_{i=a, m, s} p_{t}^{i} \bar{c}^{i}
$$

where $P_{t} \equiv\left[\sum_{i=a, m, s} \omega^{i}\left(p_{t}^{i}\right)^{1-\sigma}\right]^{\frac{1}{1-\sigma}}$ and $p_{t}^{s} \equiv\left[\psi^{\gamma}\left(p_{t}^{s m}\right)^{1-\gamma}+(1-\psi)^{\gamma}\left(p_{t}^{s h}\right)^{1-\gamma}\right]^{\frac{1}{1-\gamma}}$.

2. Intra-Temporal Problem: The household solves:

$$
\max _{\left\{c_{t}^{a}, c_{t}^{m}, c_{t}^{s m}, c_{t}^{s h}\right\}}\left(\sum_{i=a, m, s}\left(\omega^{i}\right)^{\frac{1}{\sigma}}\left(c_{t}^{i}+\bar{c}^{i}\right)^{\frac{\sigma-1}{\sigma}}\right)^{\frac{\sigma}{\sigma-1}}
$$

subject to

$$
c_{t}^{s}=\left[\psi\left(c_{t}^{s m}\right)^{\frac{\gamma-1}{\gamma}}+(1-\psi)\left(c_{t}^{s h}+\bar{c}^{s h}\right)^{\frac{\gamma-1}{\gamma}}\right]^{\frac{\gamma}{\gamma-1}},
$$

${ }^{7}$ See Online Appendix A for details. 
and

$$
p_{t}^{a} c_{t}^{a}+p_{t}^{m} c_{t}^{m}+p_{t}^{s m} c_{t}^{s m}+p_{t}^{s h} c_{t}^{s h}=P_{t} C_{t}-\sum_{i=a, m, s} p_{t}^{i} \bar{c}^{i}-p_{t}^{s h} \bar{c}^{s h} \equiv E_{t},
$$

where $E_{t}$ stands for the extended total expenditure on consumption - that is, total consumption plus home production.

The above decomposition indicates that the inter-temporal problem (P2) and the intratemporal problem (P3) can be solved separately. Also, note that the intra-temporal problem (P3) is the one that causes sectoral transformation among four consumption good sectors.

In Section 3, we estimate the intra-temporal problem (P3) using time series data for prices $\left\{p_{t}^{a}, p_{t}^{m}, p_{t}^{s m}, p_{t}^{s h}\right\}$ and extended total consumption $E_{t} .{ }^{8}$ We choose to estimate (P3) instead of the full model (P1) for two reasons. First, we are interested in estimating preference parameters in the model. Given the separation of the two problems shown in this section, it is sufficient to estimate (P3) to obtain consistent estimators of the relevant preference parameters. Second, to estimate the full model (P1), we would need to take a stand on how to bring the investment sector to the data. We know that, in the data, aggregate investment comes from the three market sectors (agriculture, manufacturing, and services) and that the composition has been changing over time. Given this feature of investment, one needs to make some simplification assumptions to model the investment sector. However, depending on the modeling choice, estimates could be different. With this in mind, we avoid making this choice in the inter-temporal problem, and focus only on the estimation of the intra-temporal problem (P3).

\subsection{Preference Specifications}

The model presented in the previous subsections encompasses the standard models of structural transformation, namely those of Kongsamut, Rebelo, and Xie (2001) and Ngai and Pissarides (2007), with the addition of home production. Since our purpose is to study the effect of home production on structural transformation, we estimate the following four different specifications, which imply different interaction mechanisms of the home and the market sectors. ${ }^{9}$

Model 1: We first impose $\bar{c}^{s}=\bar{c}^{s h}=0$. As discussed in Kongsamut, Rebelo, and Xie (2001), the parameter $\bar{c}^{s}>0$ can be interpreted as home production of services. Thus, when adding an explicit home production sector to the model, a natural restriction is to impose

\footnotetext{
${ }^{8}$ Regarding the implicit price of home good, $p_{t}^{s h}$, we discuss which data we use for it in Section 4.1.

${ }^{9}$ Note that in all specifications we restrict $\bar{c}^{m}$ to be zero, as standard in the literature.
} 
$\bar{c}^{s}=0$. In this way we can asses whether the home sector can replicate the role played by the non-homothetic parameter in the standard model.

Model 2: In the second specification, we only impose $\bar{c}^{s h}=0$. This implies that we are allowing for both an explicit home production sector and the standard non-homotheticity effect for services. Thus, the parameter $\bar{c}^{s}$ simply reflects a non-homothetic nature of services, which is not fully explained by home production.

Model 3: Third, we estimate the specification in which we only impose $\bar{c}^{s}=0$. In this case, we allow the non-homotheticity to be different between market and home services through $\bar{c}^{s h}$, while we keep the non-homothetic term for the composite service $\bar{c}^{s}$ at zero. ${ }^{10}$ By doing so, we can assess how much the non-homotheticity in home services $\bar{c}^{s h}$ improves the model's fit to the data by itself.

Model 4: Finally, we estimate the fully unrestricted model. By estimating the first three models we obtain insights into the role of each non-homothetic component. Here, we have all non-homothetic effects working together.

In the above preference specifications, the parameter $\bar{c}^{s h}$ is motivated by the empirical evidence which suggests that services categories can have different income elasticities. For instance, Eichengreen and Gupta (2013) show that the share of modern market services rises faster with income compared to that of the more traditional market services, which can also be produced at home. Although this evidence does not provide insights into the income elasticity of home services, it is reasonable to suppose that home and market services have different income elasticities. If the latter have a larger elasticity, we should expect a parameter $\bar{c}^{s h}<0$. In this case, the parameter can be interpreted as a minimum requirement of home production that the household has to provide (for instance maintenance and cleaning) before enjoying the rest of home services produced.

\section{Estimation}

This section describes the estimation. We take a two-step procedure: first, we fix the value of the elasticity of substitution parameter between home and market services by using a

\footnotetext{
${ }^{10}$ Note that in a CES aggregator with two goods, the presence of a non-homothetic term associated with one of the goods implies that the other good will also display a non-homothetic behavior. This is the case here for home services and market services. On this point, see Moro (2015).
} 
priori information from the literature; second, we estimate the rest of the parameter values from the data. ${ }^{11}$ We explain these steps in detail here.

\section{First Step}

In this step, we fix the value of the parameter $\gamma$, which governs the elasticity of substitution between home and market services. ${ }^{12}$ In the literature, one set of studies estimates the parameter $\gamma$ by using fluctuations of aggregate home hours over the business cycles (McGrattan, Rogerson, and Wright (1997); Chang and Schorfheide (2003)). Another set of studies, instead, uses household micro data for home hours (Rupert, Rogerson, and Wright (1995); Aguiar and Hurst (2007)). The estimated value of the parameter $\gamma$ ranges between 1.49 and 2.30. One important note here is that all of these estimates correspond to the elasticity of substitution between all market and non-market types of consumption. Instead, in our model the parameter only refers to the substitutability between market services and home production. As it seems reasonable to consider that market services are more substitutable with home production than other goods, we set the value of $\gamma$ equal to 2.3 , the highest one estimated in previous studies. ${ }^{13}$

\section{Second Step}

To estimate the rest of the parameters, we first derive equations for the share of each sector in the extended total consumption. Given the the set of (pre-determined) variables,

$$
\mathbf{x}_{t} \equiv\left(p_{t}^{a}, p_{t}^{m}, p_{t}^{s m}, p_{t}^{s h}, E_{t}\right)
$$

given $\gamma$, and given the rest of the parameters,

$$
\boldsymbol{\theta} \equiv\left(\sigma, \bar{c}^{a}, \bar{c}^{s}, \bar{c}^{s h}, \omega^{a}, \omega^{m}, \omega^{s}, \psi\right)
$$

problem (P3) can be solved for four shares, $\left\{\frac{p_{t}^{j} c_{t}^{j}}{E_{t}}\right\}$, where $j \in\{a, m, s m, s h\}$. Since sectoral shares sum up to one, the error covariance matrix becomes singular with four share equations. Thus, we drop one share equation, and finally have the three non-linear equations to be

\footnotetext{
${ }^{11}$ In Online Appendix B, we estimate $\gamma$ together with the rest of the parameters.

${ }^{12}$ Note that $\gamma$ does not coincide with the elasticity of substitution when non-homothetic parameters appear in the utility function. However, in our estimations we find that the difference between $\gamma$ and the true elasticity of substitution is quantitatively very small. Therefore, we consider $\gamma$ as a measure of the elasticity of substitution.

${ }^{13}$ Our strategy for the choice of the elasticity parameter is the same as the one in Rogerson (2008). In Online Appendix B, we run estimations instead by assuming $\gamma$ equal to 1.5, the lowest value estimated in the literature. We show that our main results don't change even in that case.
} 
estimated:

$$
\begin{aligned}
\frac{p_{t}^{a} c_{t}^{a}}{E_{t}} & =f_{1}\left(\mathbf{x}_{t} ; \boldsymbol{\theta}, \hat{\gamma}\right)+\epsilon_{1}, \\
\frac{p_{t}^{m} c_{t}^{m}}{E_{t}} & =f_{2}\left(\mathbf{x}_{t} ; \boldsymbol{\theta}, \hat{\gamma}\right)+\epsilon_{2}, \\
\frac{p_{t}^{s m} c_{t}^{s m}}{E_{t}} & =f_{3}\left(\mathbf{x}_{t} ; \boldsymbol{\theta}, \hat{\gamma}\right)+\epsilon_{3},
\end{aligned}
$$

where $\hat{\gamma}$ is the value of the parameter $\gamma$ from the first step. In Appendix B, we show the derivation of $\left(f_{1}, f_{2}, f_{3}\right){ }^{14}$

To estimate our demand system we closely follow previous works in the literature: Deaton (1986) and Herrendorf, Rogerson, and Valentinyi (2013). Specifically, we employ iterated feasible generalized nonlinear least square to estimate the share equations. ${ }^{15}$ For the parameters with constraints $\left(\sigma \geq 0, \omega^{a}+\omega^{m}+\omega^{s}=1, \omega^{i} \geq 0,0 \leq \psi \leq 1\right)$, we transform them into unconstrained parameters as follows;

$$
\sigma=e^{b_{1}}, \omega^{a}=\frac{1}{1+e^{b_{2}}+e^{b_{3}}}, \omega^{m}=\frac{e^{b_{2}}}{1+e^{b_{2}}+e^{b_{3}}}, \omega^{s}=\frac{e^{b_{3}}}{1+e^{b_{2}}+e^{b_{3}}}, \psi=\frac{e^{b_{4}}}{1+e^{b_{4}}} .
$$

After estimating the unconstrained parameters, we transform these back to compute point estimates and standard errors for the original parameters.

\section{Data}

One of the contributions of this paper is to estimate a structural transformation model with a home sector by using actual home production data for the U.S. We follow the income approach recently developed in the literature to construct home production data. Since the approach is based on the value-added method, we focus on consumption value added shares for our estimation. We explain below how we construct the data for our estimation.

\subsection{Home Production Data}

The basic idea of the income approach is to compute the value of home production from the market value of input factors: here home labor $L_{t}^{s h}$ and home capital $K_{t}^{s h}$. Formally, home

\footnotetext{
${ }^{14}$ See Equations (8) through (10) in the appendix.

${ }^{15}$ This methodology has also been recently used in the estimation of supply systems. See León-Ledesma, McAdam, and Willman (2010).
} 
value added of the household sector is given by

$$
\left(r_{t}^{s h}+\delta_{t}^{s h}\right) K_{t}^{s h}+w_{t}^{s h} L_{t}^{s h}
$$

where $r_{t}^{s h}$ and $\delta_{t}^{s h}$ are, respectively, the rate of return and the depreciation rate of home capital, and $w_{t}^{s h}$ is the return on home labor.

For the home capital $K_{t}^{s h}$, we use the nominal stock of consumer durables (BEA, FA Table 8.1). Unlike Bridgman (2013), we don't include gross housing value added in home capital, because the value of housing services also shows up in the household's consumption expenditure. ${ }^{16}$ For the rate of return on home capital $r_{t}^{s h}$, we use the personal income receipts from assets (BEA, NIPA Table 2.1) divided by total financial assets of the household (Board of Governors, FL152090205) net of equity in non-corporate business (Board of Governors, FL154090005). For $\delta_{t}^{s h}$ we use the depreciation of durables (BEA, FA Table 1.3).

For home labor $L_{t}^{s h}$, we use hours spent in home production constructed by Landefeld, Fraumeni, and Vojtech (2009) and Bridgman, Dugan, Lal, Osborne, and Villones (2012). These studies use multiple time use survey data and extrapolate them using CPS data on population and labor force status. For the return on home labor $w_{t}^{s h}$, we calculate hourly wage by using compensation for employees in the private households sector (BEA, NIPA Table 6.2) and the number of employees in that sector (BEA, NIPA Table 6.5), assuming that those workers spend 40 hours in working per week. ${ }^{17}$

Finally, Bridgman (2013) deflates nominal home value added with the price index of gross value added for household sector (BEA, NIPA Table 1.3.4), to obtain real home value added. We use this as the price for home value added $\left\{p_{t}^{s h}\right\}$ in our estimations below. Thus, except for the construction of home capital $K_{t}^{s h}$, we closely follow the methodology in Bridgman (2013).

\subsection{Other Data}

\section{Value Added Consumption and Price Index}

The data for value-added consumption and the corresponding price indices for agriculture, manufacturing, and services are from Herrendorf, Rogerson, and Valentinyi (2013). The advantage of using these data is that value-added consumption is computed from final con-

\footnotetext{
${ }^{16}$ This is the same approach taken for instance in Bridgman, Duernecker, and Herrendorf (2015).

${ }^{17}$ Duernecker and Herrendorf (2015) also use compensation for employees in the private households sector to compute the hourly wage rate for home labor. As they note, the main assumption here is that the marginal product of household workers is the same as the marginal product of a non-household worker who is doing household work.
} 
sumption expenditure by using the U.S. input-output matrix, in order to avoid investment components being included in consumption value-added data. ${ }^{18}$

\section{Durable Goods}

As mentioned above, we consider all durable goods as inputs for home production. Therefore, it is reasonable to remove the value of durables from the value-added consumption data, because otherwise households have durables both as consumption goods and as capital inputs for home production. Since the value of durables in consumption expenditure data consists of the value added from the three market sectors, we again follow the approach in Herrendorf, Rogerson, and Valentinyi (2013) to remove the value of durables from value added consumption. That is, we first decompose the value of final-expenditure durables into the value added of each sector using an input-output matrix, and then subtract those values from the consumption value added of each sector.

In the robustness Section 5.2, we relax the assumption that all durables are used as investment in home capital. That is, we consider the case in which some durables are treated as consumption goods, and the rest are investment goods for home capital. For example, we consider goods like jewelry and watches as directly consumed by households, while goods like home appliances form part of home capital. As we will show later, our estimation results are not affected by the relaxation of this assumption.

In the estimation, we focus on the time period between 1947 and 2010, due to the availability of consumption value added data. In order to calculate four sector shares (agriculture, manufacturing, services, and home) in extended consumption value added, we combine consumption value added data with value added of the home sector. One important assumption made here is that goods produced at home are not used for investments.

\section{Estimation Results}

In this section, we describe our estimation results.

\subsection{Benchmark Results}

Table 1 summarizes estimation results for our benchmark case. In Columns (1) through (4), we report the estimation results of Models 1 to 4, which we described in Section 2.4. In

\footnotetext{
${ }^{18}$ Several papers in this literature assume that all investment is produced in the manufacturing sector. However, the total value of investments exceeds the total value of manufacturing goods from 1999 onward in BEA's data.
} 
Column (5), we also report the results when we impose the constraint $\sigma=0$ on Model 4 . We name the model without the constraint as Model 4a, and the one with the constraint, Model 4b.

From the perspectives of the Akaike and Bayesian Information Criteria (AIC and BIC) reported in Table 1, it is evident that neither of Models 1 or 2 (Columns (1) and (2)) displays a better performance than Model 3 or 4a (Columns (3) and (4)). The poor fit of Models 1 and 2 is also visually presented in Figure 2, indicating that neither of them can correctly capture the increasing trend of market services and the decreasing trend of home services. These facts imply that the common specification in the literature, which assumes the same income elasticity of market and home services (i.e. $\bar{c}^{s h}=0$ ), cannot explain why the demand for market services has increased relative to home services over the period. Also, from the estimation result of Model 2, it is clear that the non-homotheticity term on aggregate services $\bar{c}^{s}$ doesn't help to solve the issue by itself. ${ }^{19}$

We now turn to discuss Model 3 and Model 4a. There are three points which are worth emphasizing here. First, as discussed above, Models 3 and 4a display a better fit than Models 1 and 2, suggesting that the non-homothetic term $\bar{c}^{s h}$ is key to account for the trends in both market and home service shares. ${ }^{20}$ Second, by comparing the performances of Model 3 and Model $4 \mathrm{a}$, we note that the non-homothetic term on aggregate services $\bar{c}^{s}$ plays an important role once the non-homothetic term on home services $\bar{c}^{s h}$ is introduced. This is also visually shown in Figure 3. When $\bar{c}^{s}$ is constrained at zero (Model 3), the model is not able to produce enough divergence in the patterns of home and market service shares. Instead, when $\bar{c}^{s}$ is unconstrained (Model 4a), the model's performance improves. This is because, in the former case, there is only one non-homotheticity parameter controlling the relative trends of two share series, but in the latter case, there are two parameters shaping those trends.

Third, when both the non-homotheticity term for aggregate services $\bar{c}^{s}$ and the one for home services $\bar{c}^{s h}$ are introduced, the value of $\sigma$ is no longer statistically significantly different from zero. The point estimator of $\sigma$ is 0.00459 , and the value of the heteroscedasticity-robust standard error is 0.00348 . This implies that the utility function takes a Leontief specification in terms of agricultural, manufacturing, and aggregate services. Notably, this result for $\sigma$ is similar to those in Buera and Kaboski (2009) and Herrendorf, Rogerson, and Valentinyi (2013). Given that the point estimator of $\sigma$ is not statistically significantly different from zero, we restrict the value of $\sigma$ to zero, and run the estimation of Model 4b (Column (5)

\footnotetext{
${ }^{19}$ In fact, the AIC and BIC suggest that Model 1 performs better than Model 2.

${ }^{20} \mathrm{Ngai}$ and Pissarides (2008) generate a rise of the market services share in a model with home production through homothetic preferences and differential TFP growth across sectors. Our results instead suggest that a non-homothetic component on home production is key to quantitatively account for the actual rise of the market services share in the U.S. in a model with a home sector.
} 
in Table 1). The result shows that, while the root mean squared errors are unchanged, the AIC and the BIC decrease, implying that this specification is the most preferred in terms of those measures. Therefore, we use Model $4 \mathrm{~b}$ for our counter-factual experiments in the following subsections. ${ }^{21}$

TABLE 1 - Sectoral Share Estimation Results

\begin{tabular}{|c|c|c|c|c|c|}
\hline & $\begin{array}{c}(1) \\
1\end{array}$ & $\begin{array}{c}(2) \\
2\end{array}$ & $\begin{array}{c}(3) \\
3\end{array}$ & $\begin{array}{l}(4) \\
4 a\end{array}$ & $\begin{array}{l}\text { (5) } \\
4 \mathrm{~b}\end{array}$ \\
\hline$\sigma$ & $\begin{array}{l}0.0528^{\dagger} \\
(0.0291)\end{array}$ & $\begin{array}{c}0.0259 \\
(0.0202)\end{array}$ & $\begin{array}{c}0.00331^{\dagger} \\
(0.00174)\end{array}$ & $\begin{array}{c}0.00459 \\
(0.00348)\end{array}$ & \\
\hline $\bar{c}^{a}$ & $\begin{array}{c}-176.0^{* *} \\
(3.603)\end{array}$ & $\begin{array}{c}-177.3^{* *} \\
(3.856)\end{array}$ & $\begin{array}{c}-154.7^{* *} \\
(9.276)\end{array}$ & $\begin{array}{l}-120.1^{* *} \\
(15.51)\end{array}$ & $\begin{array}{c}-129.0^{* *} \\
(13.65)\end{array}$ \\
\hline $\bar{c}^{s}$ & & $\begin{array}{l}71.14^{*} \\
(31.22)\end{array}$ & & $\begin{array}{c}4536.3^{* *} \\
(368.1)\end{array}$ & $\begin{array}{c}4360.8^{* *} \\
(323.0)\end{array}$ \\
\hline $\bar{c}^{s h}$ & & & $\begin{array}{c}-3292.4^{* *} \\
(121.3)\end{array}$ & $\begin{array}{c}-5232.1^{* *} \\
(133.8)\end{array}$ & $\begin{array}{c}-5135.3^{* *} \\
(182.8)\end{array}$ \\
\hline$\omega^{a}$ & $\begin{array}{c}0.00000158 \\
(0.00000267)\end{array}$ & $\begin{array}{l}0.0000415 \\
(0.000128)\end{array}$ & $\begin{array}{c}0.00133 \\
(0.000965)\end{array}$ & $\begin{array}{l}0.00329^{* *} \\
(0.00120)\end{array}$ & $\begin{array}{l}0.00260^{*} \\
(0.00108)\end{array}$ \\
\hline$\omega^{m}$ & $\begin{array}{c}0.180^{* *} \\
(0.00351)\end{array}$ & $\begin{array}{c}0.179^{* *} \\
(0.00562)\end{array}$ & $\begin{array}{c}0.200^{* *} \\
(0.00298)\end{array}$ & $\begin{array}{c}0.155^{* *} \\
(0.00382)\end{array}$ & $\begin{array}{c}0.157^{* *} \\
(0.00363)\end{array}$ \\
\hline$\omega^{s}$ & $\begin{array}{c}0.820^{* *} \\
(0.00351)\end{array}$ & $\begin{array}{c}0.821^{* *} \\
(0.00550)\end{array}$ & $\begin{array}{c}0.798^{* *} \\
(0.00266)\end{array}$ & $\begin{array}{c}0.841^{* *} \\
(0.00391)\end{array}$ & $\begin{array}{c}0.840^{* *} \\
(0.00356)\end{array}$ \\
\hline$\psi$ & $\begin{array}{c}0.548^{* *} \\
(0.00314)\end{array}$ & $\begin{array}{c}0.550^{* *} \\
(0.00342)\end{array}$ & $\begin{array}{c}0.591^{* *} \\
(0.00303)\end{array}$ & $\begin{array}{c}0.628^{* *} \\
(0.00525)\end{array}$ & $\begin{array}{c}0.625^{* *} \\
(0.00496)\end{array}$ \\
\hline$N$ & 64 & 64 & 64 & 64 & 64 \\
\hline$A I C$ & -1180.3 & -1177.7 & -1226.8 & -1300.7 & -1303.3 \\
\hline$B I C$ & -1148.7 & -1139.8 & -1188.9 & -1256.5 & -1265.4 \\
\hline$R M S E^{a}$ & 0.004 & 0.004 & 0.004 & 0.004 & 0.004 \\
\hline$R M S E^{m}$ & 0.009 & 0.008 & 0.012 & 0.007 & 0.007 \\
\hline$R M S E^{s m}$ & 0.067 & 0.067 & 0.042 & 0.027 & 0.027 \\
\hline$R M S E^{s h}$ & 0.065 & 0.065 & 0.037 & 0.028 & 0.029 \\
\hline
\end{tabular}

Robust standard errors in parentheses

${ }^{\dagger} p<0.10,{ }^{*} p<0.05,{ }^{* *} p<0.01$

Note: $N$ stands for the number of the sample in the estimation. $A I C$ is Akaike Information Criterion. BIC is Bayesian Information Criterion. $R M S E^{j}$ is the Root Mean Squared Error for $j$-sector's share equation.

\footnotetext{
${ }^{21}$ To interpret the estimated non-homothetic terms $\bar{c}^{a}, \bar{c}^{s}$ and $\bar{c}^{s h}$ for Model $4 \mathrm{~b}$, we compute their values relative to the consumption level of each good in 1947. These are 0.81 for $\left(-\bar{c}^{a} / c^{a}\right), 0.85$ for $\left(\bar{c}^{s} / c^{s}\right)$, and 0.73 for $\left(-\bar{c}^{s h} / c^{s h}\right)$.
} 
Figure 2 - Fitted Sectoral Shares for Model $1\left(\bar{c}^{s}=\bar{c}^{s h}=0\right)$ and Model $2\left(\bar{c}^{s h}=0\right)$
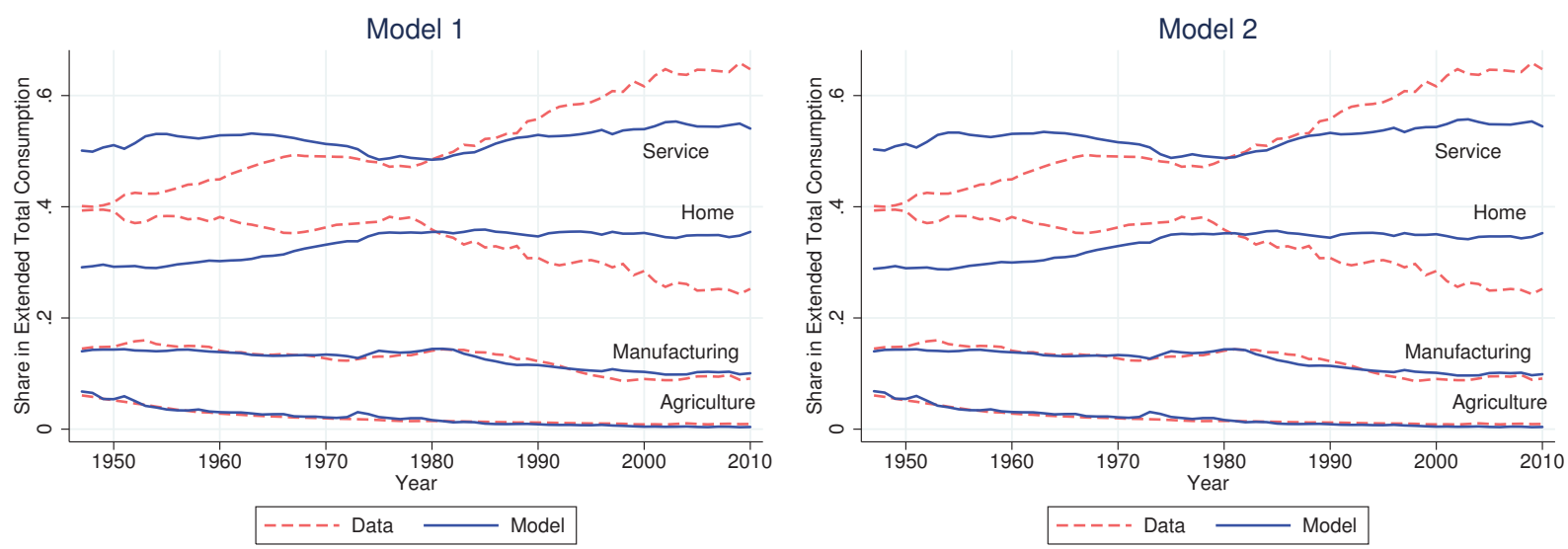

Figure 3 - Fitted Sectoral Shares for Model $3\left(\bar{c}^{s}=0\right)$ and Model 4a (no restrictions)

Model 3

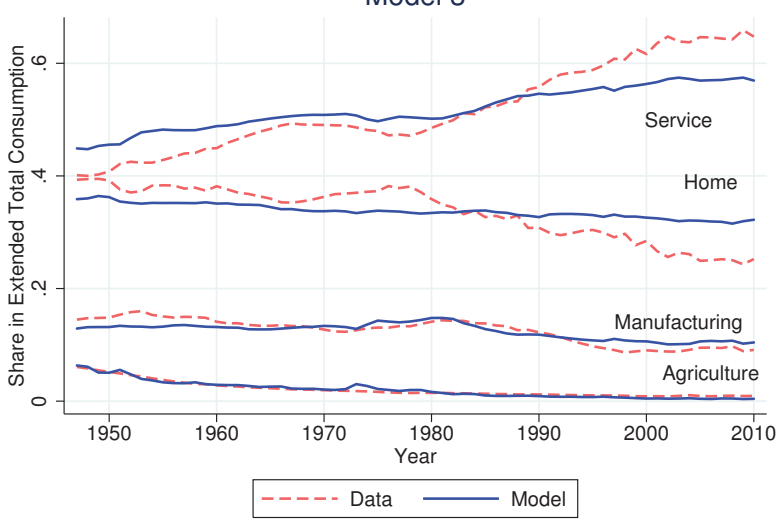

Model 4a

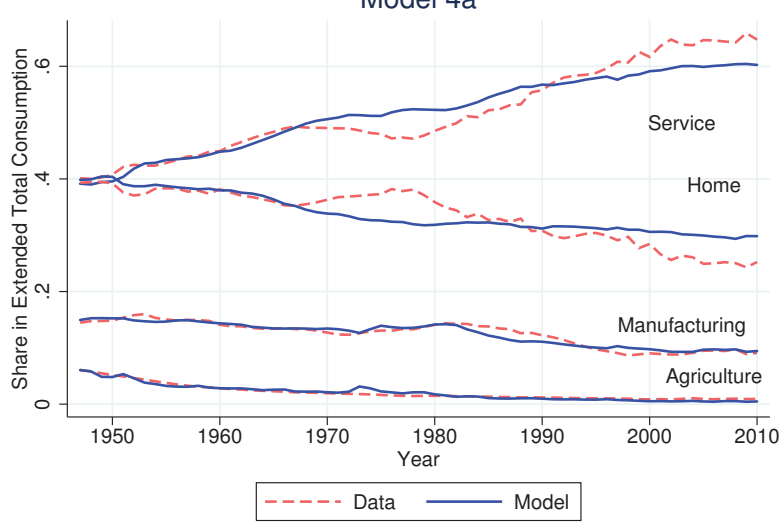

Figure 4 - Fitted Sectoral Shares for Model $4 \mathrm{~b}(\sigma=0)$

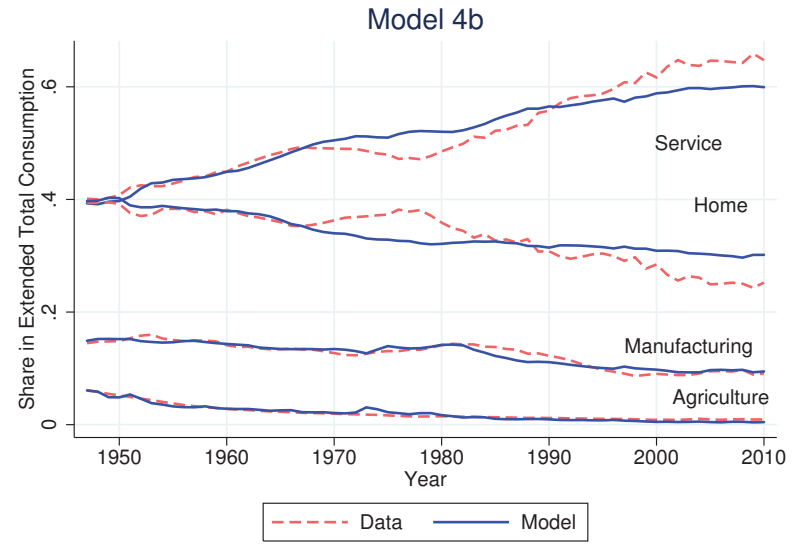


TABle 2 - Durable Good Categories

\begin{tabular}{|c|c|}
\hline & Good Categories in NIPA Table 2.4.5 \\
\hline Consumption Goods & $\begin{array}{l}\text { video, audio, photographic, and information processing equipment and media, } \\
\text { sporting equipment, supplies, guns, and ammunition, } \\
\text { sports and recreational vehicles, recreational books, musical instruments, } \\
\text { jewelry and watches, luggage and similar personal items, } \\
\text { telephone and facsimile equipment }\end{array}$ \\
\hline Investment Goods & $\begin{array}{l}\text { furniture and furnishings, household appliances, } \\
\text { glassware, tableware, and household utensils, } \\
\text { tools and equipment for house and garden, } \\
\text { therapeutic appliances and equipment, education books }\end{array}$ \\
\hline Motor Vehicles & $\begin{array}{l}\text { new motor vehicles, net purchases of used motor vehicles, } \\
\text { motor vehicle parts and accessories }\end{array}$ \\
\hline
\end{tabular}

\subsection{Robustness}

Here, we discuss the robustness of the benchmark results. For brevity, we report all estimates in Appendix A.

\section{Splitting Durable Goods}

As we discussed in Section 4, we consider all durable goods as investment in home capital in the benchmark case. However, while some types of goods are more likely to be used for home production (e.g. home appliances), some others are more naturally assigned to consumption (e.g. jewelry and watches). Therefore, it seems reasonable to check whether our estimation results are robust when we relax the assumption that all durables are used as capital inputs for home production.

For this purpose, we first classify the final durable good expenditure in two categories: direct consumption goods and capital inputs for home production. Then, we calculate consumption value added from the former, and use the latter to compute home value added. We refer to BEA's NIPA Table 2.4.5 when dividing final durable good expenditures into the two categories. We then apply the input-output matrices in Herrendorf, Rogerson, and Valentinyi (2013) to those which we classified as consumption goods in order to convert consumption expenditure into consumption value added. The created consumption value-added data are then added to the consumption value added of each market sector. We also refer to BEA's FA Table 8.1 when constructing the stock of durable goods, which is consistent with the way we split them in consumption expenditure data. ${ }^{22}$ The data of the stock are then

\footnotetext{
${ }^{22}$ NIPA Table 2.4.5 and FA Table 8.1 have almost the same structure in terms of the classification of durable goods. Therefore, it is possible to construct the stock of durable goods consistent with the way we split durable goods in the consumption expenditure data.
} 
used to construct home capital. Table 2 shows our classification of durable goods into the two categories. One type of good that is likely to be used extensively both for consumption and for home capital is motor vehicles. Therefore, for motor vehicles, we consider two cases: first we include them in consumption goods (Case 1); and second we consider them as home capital investment (Case 2).

Table A.1 and Table A.2 in Appendix A present the results for each case. As shown in the tables, none of the findings in our benchmark estimation change significantly in both cases. Notably, our finding that the non-homotheticity parameter $\bar{c}^{\text {sh }}$ significantly improves the model's performance is fairly robust even after we introduce the new definitions for home capital goods.

\section{Excluding Government Consumption}

Government consumption is externally imposed on the household, and there is not a price at which households optimally decide the quantity to purchase. Therefore, it doesn't seem to be fully appropriate to study structural transformation by considering consumption purchased by the government sector. For this reason, we remove government spending from consumption value added data, and re-estimate our model to check the robustness of our benchmark results. In this exercise, we are implicitly assuming that households are taxed by the government to run a balanced budget, and that government spending does not provide utility to the households. Table A.3 in Appendix A presents estimation results when we exclude government's spending from the consumption value-added data. Again, none of the findings in our benchmark estimation change significantly even when we control for the government's spending.

\section{Counter-Factual Experiment}

As documented in Bridgman (2013), home labor productivity grows roughly at the same pace as labor productivity in the market economy during the period 1947 to 1978 (2.0\% versus $2.1 \%$ ). After that period, however, the growth rate stagnates around zero (see Figure 5, left panel). To precisely date the slowdown, we test for multiple structural breaks using the approach proposed in Bai and Perron (1998, 2003). We find that, at $1 \%$ significance level, there is a break between 1978 and 1979, after which the mean growth rate of home labor productivity decreases by $2.8 \% .{ }^{23}$ Given its magnitude and long lasting duration, it is reasonable to ask how large the quantitative effect of this slowdown is for the process of

\footnotetext{
${ }^{23}$ See Online Appendix D for details.
} 
Figure 5 - Counter-Factual Experiment: No Slow-Down in Home Labor Productivity
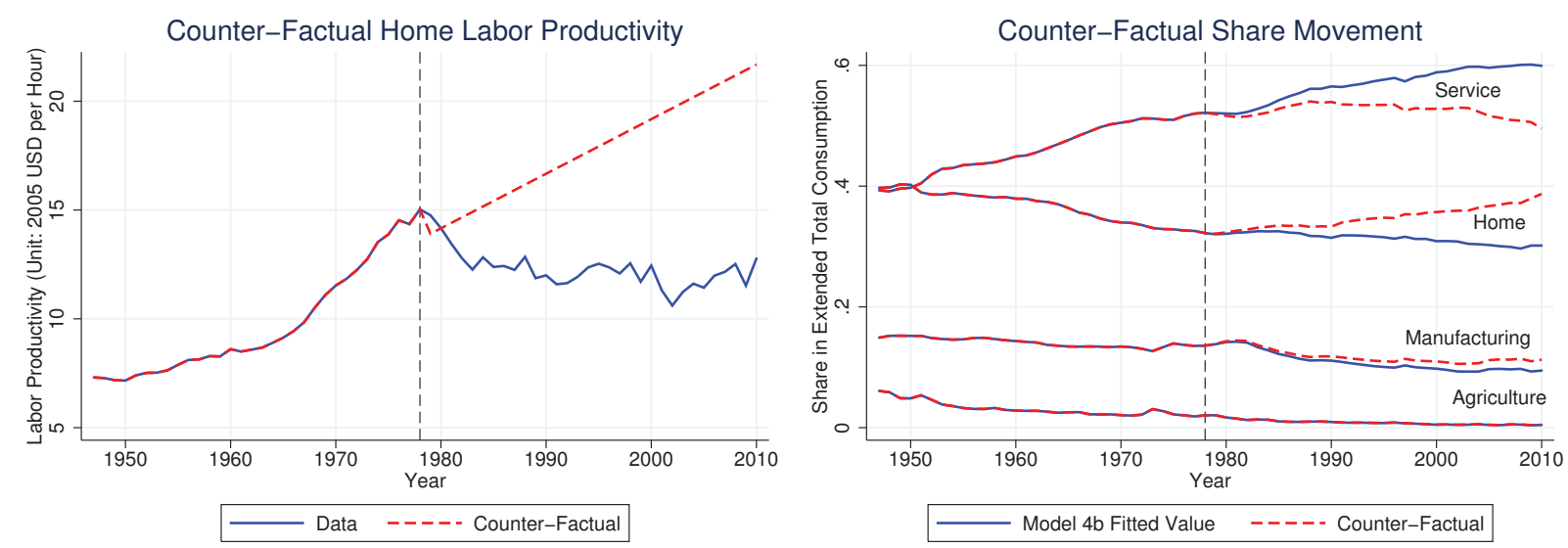

structural transformation. In this section, we address this question by running a counterfactual experiment in which, other conditions being equal, there is no slow-down in labor productivity during the period 1979 to 2010.

More precisely, we assume that in the household problem, all market prices and total expenditure evolve as observed in the data, while the price of the home good evolves differently from the data due to a counter-factual evolution of home labor productivity $A_{t}^{* s h}$. By using the first order conditions of the firm in the home sector, we can derive

$$
\frac{\Delta p_{t}^{s h}}{p_{t}^{s h}}=\frac{\Delta w_{t}}{w_{t}}-\frac{\Delta A_{t}^{* s h}}{A_{t}^{* s h}},
$$

which defines the relationship between the growth rate of the home price and that of home labor productivity. ${ }^{24}$ Using Equation (6) we can calculate the counter-factual price of the home good from the counter-factual home labor productivity. ${ }^{25}$ To run the experiment, we use Model $4 \mathrm{~b}$, which provides the best fit of the data. The outcome of the exercise is displayed in the right panel of Figure 5.

Without the slowdown in home labor productivity, the divergence between the share of market services and the home share over the period is substantially reduced. This experiment thus suggests that, holding other conditions equal, the slowdown in home labor productivity

${ }^{24}$ Using the first order conditions of the firm in the home sector we can derive

$$
p_{t}^{s h}=\frac{w_{t}}{(1-\alpha) A_{t}^{s h}\left(\frac{K_{t}^{s h}}{L_{t}^{s h}}\right)^{\alpha}}=\frac{w_{t}}{(1-\alpha)\left(\frac{Y_{t}^{s h}}{L_{t}^{s h}}\right)}=\frac{w_{t}}{(1-\alpha) A_{t}^{* s h}} .
$$

By taking total differentiation on both sides, we reach the equation in the text.

${ }^{25}$ As the counter-factual home labor productivity grows on average $2.8 \%$ higher than the actual growth rate, the growth rate of the counter-factual price from 1979 onwards will be lower than the actual growth rate by $2.8 \%$. 
TABle 3 - Counter-Factual Experiment: No Slowdown in Home Labor Productivity

\begin{tabular}{lccccccccc}
\hline & \multicolumn{3}{c}{ Ext. Consumption Share } & \multicolumn{3}{c}{ Consumption Share } & \multicolumn{3}{c}{ Consumption per Capita } \\
& Bench & CF & $\Delta \%$ & Bench & CF & $\Delta \%$ & Bench & CF & $\Delta \%$ \\
\hline Agriculture & 0.005 & 0.005 & 6.9 & 0.006 & 0.008 & 21.8 & 228 & 244 & 6.9 \\
Manufacturing & 0.095 & 0.113 & 19.1 & 0.135 & 0.184 & 35.8 & 4751 & 5661 & 19.1 \\
Market Services & 0.599 & 0.495 & -17.3 & 0.858 & 0.808 & -5.8 & 30124 & 24899 & -17.3 \\
Home Services & 0.302 & 0.387 & 28.4 & - & - & - & 15159 & 33927 & 123.8 \\
\hline
\end{tabular}

Note: Consumption per capita is in 2005 U.S. dollars. The numbers in " $\Delta \%$ " columns are percent changes from the benchmark fitted value (Model 4b).

is crucial in accounting for the whole rise of the market services share. Models that do not have an explicit home production sector might overlook an important factor which affects the rise of market services.

The first three columns in Table 3 report the extended consumption shares in the benchmark estimation (the fitted values of Model 4b) and in the counter-factual for the year 2010. The market services share is 0.60 in the benchmark and 0.50 in the counter-factual experiment. This difference is compensated by the home share, which is 0.30 in the benchmark and 0.39 in the counter-factual. These numbers suggest a large substitution of market services by home services without the slowdown in home labor productivity. A similar result holds for the services share when we look at the (market) consumption shares reported in the second three columns in the table. Services is 0.86 in the benchmark and 0.81 in the counter-factual. This difference amounts to a $5.8 \%$ decrease of the market service share. The last three columns in the table report consumption per capita in 2005 U.S. dollars. As market prices do not change in the counter-factual, the patterns are the same as those of the extended consumption shares except for home services. To conclude, the results in the counter-factual experiment indicate that the slowdown in the home labor productivity has quantitatively a significant impact on the rise of the market service sector over the period of the analysis. 


\section{Disaggregating the Service Sector}

In our benchmark specification in Section 2, we assume that all market services enter the aggregator with home services, thus implicitly assuming that they are all substitutable with home services to the same extent. Although this is the specification most commonly used in the literature (see for instance Rogerson (2008), Ngai and Petrongolo (2013), Rendall (2015)), one might think that some market services do not have a home counterpart. For instance, finance, health and educational services don't seem to be substitutable with home services. Therefore, it is important to further disaggregate market services into home substitutables and non-substituables, and to write and estimate a model which explicitly considers these two sectors. In this section, we explore this possibility.

\subsection{Model}

We assume the same general structure of the model as in Section 2, and introduce two types of market services. The consumption index of the representative household in period $t$ becomes

$$
C_{t}=\left(\sum_{i=a, m, s n, s c}\left(\omega^{i}\right)^{\frac{1}{\sigma}}\left(c_{t}^{i}+\bar{c}^{i}\right)^{\frac{\sigma-1}{\sigma}}\right)^{\frac{\sigma}{\sigma-1}} .
$$

Here $c^{a}$ stands for the household's consumption on agricultural goods, $c^{m}$ on manufacturing goods, $c^{s n}$ on modern services (i.e. market services which are non-substitutable to home), and $c^{s c}$ on traditional services. The latter is a composite of services in the market $c^{s m}$ and home produced services $c^{s h}$ :

$$
c_{t}^{s c}=\left[\psi\left(c_{t}^{s m}\right)^{\frac{\gamma-1}{\gamma}}+(1-\psi)\left(c_{t}^{s h}+\bar{c}^{s h}\right)^{\frac{\gamma-1}{\gamma}}\right]^{\frac{\gamma}{\gamma-1}} .
$$

The budget constraint of the household is

$$
p_{t}^{a} c_{t}^{a}+p_{t}^{m} c_{t}^{m}+p_{t}^{s n} c_{t}^{s n}+p_{t}^{s m} c_{t}^{s m}+p_{t}^{s h} c_{t}^{s h}=E_{t}
$$

where now $p_{t}^{s n}$ is the price of modern services, $p_{t}^{s m}$ is the price of traditional services in the market and, as before, $p_{t}^{s h}$ is the implicit price of the home good. ${ }^{26}$ We estimate two versions of the model. ${ }^{27}$

\footnotetext{
${ }^{26}$ Note that the separation between the inter-temporal problem and the intra-temporal problem also applies here. This is easily seen once noted that the utility function takes the same form as in (1)-(2) but with an additional type of consumption.

${ }^{27}$ Again, in all specifications, we assume $\bar{c}^{m}$ equal to zero.
} 
TABLE 4 - Modern and Traditional Market Services in the Consumption Expenditure

\begin{tabular}{ll}
\hline & Service Categories in NIPA Table 2.4.5 \\
\hline Modern Market Services & Housing and Utilities (49), Health Care (60) \\
& Transportation Services (68), Recreation Services (76) \\
& Financial Services and Insurance (86), Communication (96) \\
& Education Services (100), Professional and Other Services (121) \\
& Social Services and Religious Activities (120) \\
\hline Traditional Market Services & Food Services and Accommodations (81) \\
& Personal Care and Clothing Services (105), Household Maintenance (107) \\
\hline
\end{tabular}

Note: The numbers in brackets in the above table correspond to the line numbers in NIPA Table 2.4.5.

Model 5 We impose $\bar{c}^{s h}=0$, which implies the same income elasticity for traditional market services and home services, while we keep the differential income elasticity between modern services and traditional services.

Model 6 We estimate the fully unrestricted model so that income elasticity is allowed to be different for the three types of services.

\subsection{Data}

In order to estimate the model presented in Section 7.1, we need to construct the consumption value added and corresponding price data for the modern and traditional market service sectors. To create the consumption value added data, we follow the approach in Herrendorf, Rogerson, and Valentinyi (2013). That is, first, within final consumption expenditure data, we define two categories, modern and traditional market services. Second, we remove the distributional costs from the final consumption expenditure on goods and move them into expenditure on modern services. ${ }^{28}$ Third, we create the input-output matrices which have the modern and traditional market service sectors. Finally, we apply the input-output matrices to final consumption expenditure to convert them into consumption value added.

Table 4 shows how we divide market services into the modern and traditional categories in the consumption expenditure data. ${ }^{29}$ In the data, the services that appear to have a clear home-counterpart are: "food services and accommodations", "personal care and clothing services", and "household maintenance". Thus, we consider these as traditional market services, and the rest as modern market services. In order to create the input-output matrices, we

\footnotetext{
${ }^{28}$ This procedure converts final consumption expenditure measured in purchaser's prices into the one measured in producer's prices. We move distributional costs to the modern service sector because our definition of modern services includes transportation services as shown later.

${ }^{29}$ We use NIPA Table 2.4.5 to create the modern and traditional market service expenditure data.
} 
apply a similar categorization. The details on how we construct the input-output matrices are documented in Online Appendix C.

To create the corresponding prices, we use nominal value added, chain-weighted valueadded quantities, and chain-weighted value-added prices at industry level from BEA's GDPby-Industry Table. Since chain-weighted quantities are not additive, we apply the so called cyclical expansion procedure to aggregate quantities into the four categories (agriculture, manufacturing, modern market services, and traditional market services). ${ }^{30}$ We then use them to calculate the aggregate prices for the four categories. In Online Appendix C, we describe how we construct prices in detail.

\subsection{Estimation Results}

Columns (1) and (2) in Table 5 summarize the estimation results for Models 5 and 6, respectively. Also, Figures 6 and 7 provide their graphical fit to the data. First, note that, in Column (2) in Table 5, the non-homotheticity parameter $\bar{c}^{s h}$ is estimated to be negative. Also, Model 6 outperforms Model 5 in terms of the AIC and BIC statistics. These two facts imply that home services exhibit lower income elasticity than traditional market services, and that the difference in income elasticities still plays an important role to account for the movement of home service and other shares. These results are consistent with those in the benchmark case.

Second, note that when we disaggregate the market service sector into modern and traditional ones, the point estimate of $\sigma$ is no longer close to zero. The estimated value is 1.48 in Model 5 and 1.24 in Model 6. This result is due to the fact that the elasticity of substitution between modern and traditional services is larger than that among agricultural goods, manufacturing goods, and total market services. Therefore, the estimated $\sigma$ increases once the service sector is disaggregated into the two sectors.

\footnotetext{
${ }^{30}$ For an explanation of the cyclical expansion procedure, see Herrendorf, Rogerson, and Valentinyi (2013).
} 
TABLE 5 - Disaggregated Service Sector: Estimation Results

\begin{tabular}{|c|c|c|}
\hline & $\begin{array}{l}(1) \\
\text { Disagg. of Services } 5\end{array}$ & $\begin{array}{l}(2) \\
\text { Disagg. of Services } 6\end{array}$ \\
\hline$\sigma$ & $\begin{array}{l}1.476^{* *} \\
(0.0549)\end{array}$ & $\begin{array}{l}1.238^{* *} \\
(0.0182)\end{array}$ \\
\hline $\bar{c}^{a}$ & $\begin{array}{c}-154.4^{* *} \\
(3.657)\end{array}$ & $\begin{array}{c}-137.9^{* *} \\
(3.693)\end{array}$ \\
\hline $\bar{c}^{s n}$ & $\begin{array}{c}12106.4^{* *} \\
(620.3)\end{array}$ & $\begin{array}{c}19809.3^{* *} \\
(830.2)\end{array}$ \\
\hline $\bar{c}^{s c}$ & $\begin{array}{c}2101.5^{* *} \\
(115.4)\end{array}$ & $\begin{array}{c}7714.1^{* *} \\
(426.5)\end{array}$ \\
\hline $\bar{c}^{s h}$ & & $\begin{array}{c}-4839.5^{* *} \\
(154.3)\end{array}$ \\
\hline$\omega^{a}$ & $\begin{array}{l}0.00189^{* *} \\
(0.000289)\end{array}$ & $\begin{array}{l}0.00243^{* *} \\
(0.000232)\end{array}$ \\
\hline$\omega^{m}$ & $\begin{array}{l}0.0806^{* *} \\
(0.00201)\end{array}$ & $\begin{array}{l}0.0603^{* *} \\
(0.00200)\end{array}$ \\
\hline$\omega^{s n}$ & $\begin{array}{c}0.579^{* *} \\
(0.00920)\end{array}$ & $\begin{array}{c}0.599^{* *} \\
(0.00387)\end{array}$ \\
\hline$\omega^{s c}$ & $\begin{array}{c}0.339^{* *} \\
(0.00780)\end{array}$ & $\begin{array}{c}0.338^{* *} \\
(0.00421)\end{array}$ \\
\hline$\psi$ & $\begin{array}{c}0.256^{* *} \\
(0.00249)\end{array}$ & $\begin{array}{c}0.325^{* *} \\
(0.00402)\end{array}$ \\
\hline$N$ & 64 & 64 \\
\hline$A I C$ & -1756.8 & -1824.5 \\
\hline$B I C$ & -1706.2 & -1767.6 \\
\hline$R M S E^{a}$ & 0.003 & 0.003 \\
\hline$R M S E^{m}$ & 0.019 & 0.015 \\
\hline$R M S E^{s n}$ & 0.026 & 0.021 \\
\hline$R M S E^{s m}$ & 0.009 & 0.009 \\
\hline$R M S E^{s h}$ & 0.020 & 0.017 \\
\hline
\end{tabular}

Robust standard errors in parentheses

${ }^{\dagger} p<0.10,{ }^{*} p<0.05,{ }^{* *} p<0.01$ 
FiguRE 6 - Disaggregated Service Sector: Model $5\left(\bar{c}^{s h}=0\right)$
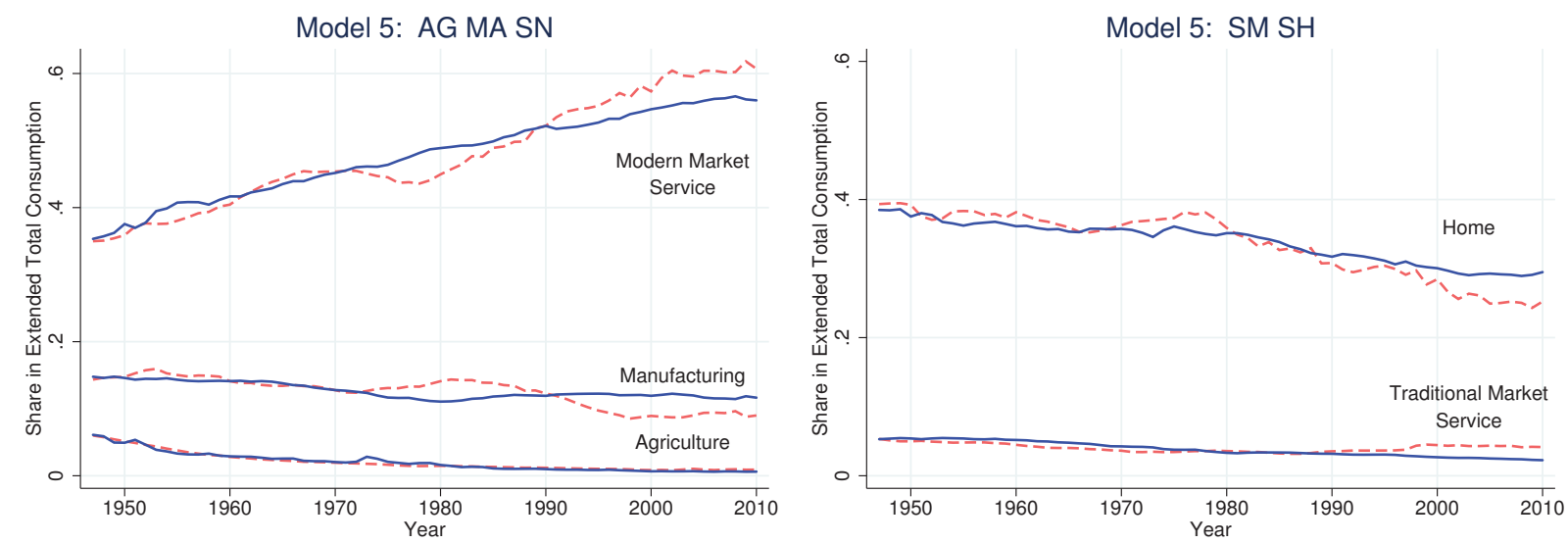

FiguRE 7 - Disaggregated Service Sector: Model 6 (no restrictions)
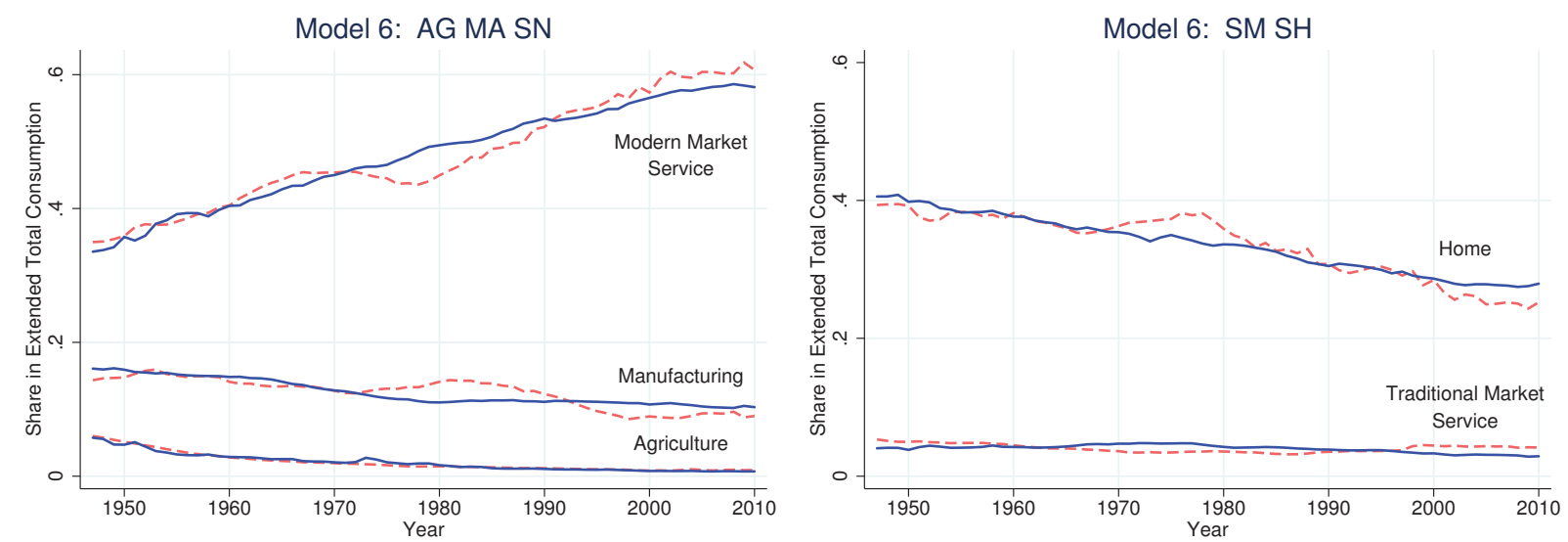
TABLE 6 - Counter-Factual Experiment in the Disaggregated Case

\begin{tabular}{lccccccccc}
\hline & \multicolumn{3}{c}{ Ext. Consumption Share } & \multicolumn{3}{c}{ Consumption Share } & \multicolumn{4}{c}{ Consumption per Capita } \\
& Bench & CF & $\Delta \%$ & Bench & CF & $\Delta \%$ & Bench & CF & $\Delta \%$ \\
\hline Agriculture & 0.007 & 0.007 & -4.1 & 0.010 & 0.011 & 9.0 & 357 & 342 & -4.1 \\
Manufacturing & 0.103 & 0.095 & -7.3 & 0.143 & 0.150 & 5.3 & 5162 & 4786 & -7.3 \\
Market Services & 0.610 & 0.531 & -12.9 & 0.847 & 0.839 & -1.0 & 30655 & 26704 & -12.9 \\
$\quad$ Modern & 0.581 & 0.507 & -12.8 & 0.807 & 0.800 & -0.9 & 29193 & 25464 & -12.8 \\
Traditional & 0.029 & 0.025 & -15.2 & 0.040 & 0.039 & -3.6 & 1462 & 1240 & -15.2 \\
Home Services & 0.280 & 0.367 & 30.8 & - & - & - & 14088 & 32134 & 128.1 \\
\hline
\end{tabular}

Note: Consumption per capita is in 2005 U.S. dollars. The numbers in " $\Delta \%$ " columns are percent changes from the benchmark fitted value (Model 6).

\subsection{Counter-Factual Experiment}

In this subsection, we use the estimate of Model 6, and run the same counter-factual experiment as in Section 6. That is, we analyze the movement of the sector shares assuming that there is no slow-down in labor productivity during the period 1979 to 2010 . The results of this counter-factual experiment are reported in Table 6 .

Even in the disaggregated case, we obtain a significant rise of the home service share $(30.8 \%)$ and a sharp decline of the market service share $(-12.9 \%)$ in extended total consumption when there is no slowdown in the labor productivity. This result might appear counter-intuitive at first glance, because one might expect that a drop of home labor productivity would mainly affects traditional market services through substitution. As traditional market services represent only a small share of the economy, the total effect on market services is expected to be small.

To see why it is not the case here, remember that our estimate of the elasticity of substitution parameter $\sigma$ in the disaggregated case is substantially higher than the one in the benchmark case. This result arises because modern market services and traditional market services have a higher substitutability than that among agricultural goods, manufacturing goods, and total market services. Since the parameter $\sigma$ governs the elasticity of substitution of all consumption goods, the higher value for that parameter implies a higher substitution effect between home services and all other goods and services. Therefore, when home services rise in the counter-factual, we see a large decline in the extended consumption share of all the other sectors (-4.1\% for agriculture and $-7.3 \%$ for manufacturing), especially in the market service sector (by -12.9\%). These results indicate that there is a significant effect of the home labor productivity slowdown on the economy even when we disaggregate the service sector. 
FiguRE 8 - Fraction of Home Hours in Total Working Hours

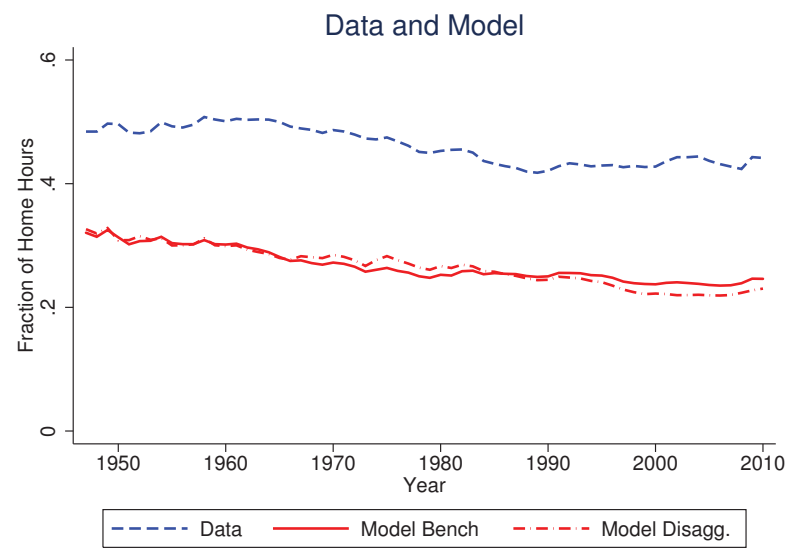

\section{Implications for Home and Market Hours}

Several studies in the literature (Aguiar and Hurst (2007); Ramey (2009); Ramey and Francis (2009)) have documented changing patterns of hours spent in market and home activities in the U.S. over the second half of the last century. As these changes might reflect the effects of structural transformation, we investigate here whether our model predicts an evolution of home hours that is consistent with that observed in the data. To do this, we generate the fraction of home hours in total working hours in the model, and compare it with the one in the data.

We use the data on weekly market and home hours from Ramey and Francis (2009) to calculate the fraction of home hours. This is the only data set of household's time use that covers the entire period of our analysis, 1947 through 2010, for both home and market hours. ${ }^{31}$ We compute the model's counterpart of the fraction of home hours as the share of the home value added in the extended GDP. ${ }^{32}$ Figure 8 plots the fraction of home hours in total working hours in the model and in the data. The two red lines are the benchmark model (solid line) and the disaggregated model (dashed line), respectively. The blue dashed line is the data. Note that both the benchmark and disaggregated models replicate the declining trend in the fraction of home hours in the data reasonably well.

Although the model performs well in replicating the trend in hours, a question that can arise here is why the two models are not able to match the level of the fraction of home hours.

\footnotetext{
${ }^{31}$ Ramey and Francis (2009) combine data from multiple sources, and develop comprehensive measures of time spent in market work, home production, schooling, and leisure in the United States from 1900 to 2006. Their updated data series cover the period through 2012.

${ }^{32}$ The underlying assumption of this calculation is that there are no factor distortions across sectors. This assumption implies that the value added share and the labor share in each sector are equal in equilibrium.
} 
TABLE 7 - Wedges between the Market and the Home Wages

\begin{tabular}{lcc}
\hline Wedge $\left(\tau_{t}\right)$ & Benchmark Case & Disaggregated Case \\
\hline Mean & 1.35 & 1.37 \\
Standard Deviation & 0.16 & 0.21 \\
\hline
\end{tabular}

To understand the reason, recall that in standard models of structural transformation the value added share and the labor share are equal in equilibrium. Therefore, once the model is estimated using the data for value added shares, it will deliver the same behavior for the labor shares. This means that, as long as there are differences in the two types of shares in the data, the model cannot account for both types at the same time. This is an important shortcoming in the standard structural change models that try to account for the evolution of value added shares, as discussed in Buera and Kaboski (2009) and Herrendorf, Rogerson, and Valentinyi (2014).

To account for the gap between value added shares and labor shares, we take an approach similar to that in Buera and Kaboski (2009) and assume that there is a wedge which captures sectoral differences in human capital and factor distortions between the market sectors and the home sector. More specifically, we assume that $w_{t}=w_{t}^{s h}\left(1+\tau_{t}\right)$, where $\tau_{t}$ is the wedge, $w_{t}$ is the market wage, and $w_{t}^{s h}$ is the home wage. By using first order conditions of firms in each sector with respect to labor, we can write that

$$
\frac{L_{t}^{s h}}{L_{t}^{m k}}=\left(\frac{p_{t}^{s h} Y_{t}^{s h}}{G D P_{t}}\right)\left(\frac{w_{t}}{w_{t}^{s h}}\right)=\left(\frac{p_{t}^{s h} Y_{t}^{s h}}{G D P_{t}}\right)\left(1+\tau_{t}\right) .
$$

where $L_{t}^{s h}$ is total hours in the home sectors, and $L_{t}^{m k}$ is total hours in the market sectors and $G D P_{t}$ is the total value of production of the market sectors. We then use (7) to find a value for the wedge $\tau_{t}$ for each period that makes the predicted employment share in the model the same as the one in the data.

The mean and the standard deviation of the obtained values for $\left\{\tau_{t}\right\}_{t=1947}^{2010}$ are reported in Table 7. There are two points that are worth to emphasize in the table. First, the computed wedge between home and market is large, with a mean of 1.35 for the benchmark case, and 1.37 for the disaggregated case. These results imply that there are significant differences in human capital or in factor distortions between home and market sectors during the period of the analysis. Second, the standard deviation of the wedge is low compared to its mean, 0.16 for the benchmark case, and 0.21 for the disaggregated case. This means that the wedge between market and home sectors is fairly stable over the period. In summary, while our model can replicate the trend of the home and market hours, it implies a large and fairly 
constant wedge between home and market sectors during the period of the analysis.

\section{Conclusion}

In this paper we present a model of structural transformation with a home production sector and estimate it by using U.S. data. We find that the specification of the model with a different degree of non-homotheticity between home and market services provides the best fit of the data. In particular, the estimation provides an income elasticity of home services lower than that of market services. This is in line with recent empirical evidence suggesting that the share of market services that can be also produced at home grows more slowly with income compared to that of market services which don't have home counterparts.

The estimated model is then used to run a counter-factual experiment. In particular, we measure the contribution of the slowdown in home productivity growth to the rise of the market services share in the U.S. We find that without the slowdown, the magnitude of structural transformation is significantly lower. This result suggests that home productivity plays an important role for structural transformation. 


\section{References}

Aguiar, M., And E. Hurst (2007): "Measuring Trends in Leisure: The Allocation of Time Over Five Decades," The Quarterly Journal of Economics, 122(3), 969-1006.

BAI, J., And P. Perron (1998): "Estimating and Testing Linear Models with Multiple Structural Changes," Econometrica, 66(1), 47-78.

(2003): "Computation and Analysis of Multiple Structural Change Models," Journal of Applied Econometrics, 18(1), 1-22.

Benhabib, J., R. Rogerson, and R. Wright (1991): "Homework in Macroeconomics: Household Production and Aggregate Fluctuations," Journal of Political Economy, 99(6), 1166-87.

Bridgman, B. (2013): "Home Productivity," Working Paper, Bureau of Economic Analysis.

Bridgman, B., G. Duernecker, and B. Herrendorf (2015): "Structural Transformation, Marketization, and Household Production around the World," Working Paper, University of Mannheim.

Bridgman, B., A. Dugan, M. Lal, M. Osborne, and S. Villones (2012): "Accounting for household production in the national accounts, 1965-2010," Survey of Current Business, 92(5), 23-36.

Buera, F. J., And J. P. Kaboski (2009): "Can Traditional Theories of Structural Change Fit the Data?," Journal of the European Economic Association, 7(2-3), 469-477.

(2012a): "The Rise of the Service Economy," The American Economic Review, 102(6), 2540-69.

(2012b): "Scale and the Origins of Structural Change," Journal of Economic Theory, $147(2), 684-712$.

Chang, Y., And F. Schorfheide (2003): "Labor-Supply Shifts and Economic Fluctuations," Journal of Monetary Economics, 8(50), 1751-1768.

Deaton, A. (1986): "Demand Analysis," Handbook of Econometrics, 3, 1767-1839.

Duernecker, G., And B. Herrendorf (2015): "On the Allocation of Time-A Quantitative Analysis of the US and France," Working Paper, University of Mannheim. 
Eichengreen, B., And P. Gupta (2013): "The Two Waves of Service-Sector Growth," Oxford Economic Papers, 65(1), 96-123.

Greenwood, J., And Z. Hercowitz (1991): "The Allocation of Capital and Time over the Business Cycle," Journal of Political Economy, 99(6), 1188-214.

Hansen, B. E. (2001): "The New Econometrics of Structural Change: Dating Breaks in US Labour Productivity," Journal of Economic Perspectives, 15(4), 117-128.

Herrendorf, B., R. Rogerson, and Á. Valentinyi (2013): "Two Perspectives on Preferences and Structural Transformation," The American Economic Review, 103(7), $2752-2789$.

Herrendorf, B. M., R. Rogerson, and Á. Valentinyi (2014): "Growth and Structural Transformation," Handbook of Economic Growth, 2, 855-941.

KendrICK, J. W. (1979): "Expanding Imputed Values in the National Income and Product Account," Review of Income and Wealth, 25(4), 349-363.

Kongsamut, P., S. Rebelo, And D. Xie (2001): "Beyond Balanced Growth," The Review of Economic Studies, 68(4), 869-882.

Landefeld, J. S., B. M. Fraumeni, and C. M. Vojtech (2009): "Accounting for Household Production: A Prototype Satellite Account Using the American Time Use Survey," Review of Income and Wealth, 55(2), 205-225.

Landefeld, J. S., And S. H. MCCulla (2000): "Accounting for Nonmarket Household Production within a National Accounts Framework," Review of Income and Wealth, 46(3), 289-307.

León-Ledesma, M. A., P. McAdam, and A. Willman (2010): "Identifying the Elasticity of Substitution with Biased Technical Change," The American Economic Review, 100(4), 1330-1357.

McGrattan, E. R., R. Rogerson, and R. Wright (1997): "An Equilibrium Model of the Business Cycle with Household Production and Fiscal Policy," International Economic Review, 38(2), 267-90.

Moro, A. (2015): "Structural Change, Growth, and Volatility," American Economic Journal: Macroeconomics, 7(3), 259-94. 
Ngai, L. R., and B. Petrongolo (2013): "Gender Gaps and the Rise of the Service Economy," Working Paper, London School of Economics.

Ngai, L. R., And C. A. Pissarides (2007): "Structural Change in a Multisector Model of Growth," The American Economic Review, 97(1), 429-443.

(2008): "Trends in Hours and Economic Growth," Review of Economic Dynamics, 11(2), 239-256.

RAmey, V. A. (2009): "Time spent in home production in the twentieth-century United States: new estimates from old data," The Journal of Economic History, 69(1), 1-47.

Ramey, V. A., And N. Francis (2009): "A Century of Work and Leisure," American Economic Journal: Macroeconomics, 1(2), 189-224.

Rendall, M. (2015): "Female Market Work, Tax Regimes, and the Rise of the Service Sector," Working Paper, University of Zurich.

Ríos-Rull, J.-V. (1993): "Working in the Market, Working at Home, and the Acquisition of Skills: A General-Equilibrium Approach," The American Economic Review, 83(4), 893907.

Rogerson, R. (2008): "Structural Transformation and the Deterioration of European Labor Market Outcomes," Journal of Political Economy, 116(2), 235-259.

Rupert, P., R. Rogerson, and R. Wright (1995): "Estimating Substitution Elasticities in Household Production Models," Economic Theory, 6(1), 179-193. 


\section{Appendix}

\section{A Additional Tables}

TABle A.1 - Splitting Durable Goods, Case 1: Estimation Results

\begin{tabular}{|c|c|c|c|c|c|}
\hline & (1) & (2) & $\begin{array}{c}(3) \\
3\end{array}$ & (4) & (5) \\
\hline$\sigma$ & $\begin{array}{l}0.0747^{*} \\
(0.0351)\end{array}$ & $\begin{array}{c}0.00186^{* *} \\
(0.000473)\end{array}$ & $\begin{array}{c}0.000144^{*} \\
(0.0000618)\end{array}$ & $\begin{array}{c}0.000176^{* *} \\
(0.0000501)\end{array}$ & \\
\hline $\bar{c}^{a}$ & $\begin{array}{l}-177.0^{* *} \\
(3.837)\end{array}$ & $\begin{array}{c}-177.7^{* *} \\
(3.571)\end{array}$ & $\begin{array}{l}-150.4^{* *} \\
(8.326)\end{array}$ & $\begin{array}{l}-128.6^{* *} \\
(12.36)\end{array}$ & $\begin{array}{l}-128.6^{* *} \\
(11.63)\end{array}$ \\
\hline $\bar{c}^{s}$ & & $\begin{array}{c}1606.4^{* *} \\
(322.7)\end{array}$ & & $\begin{array}{c}3817.1^{* *} \\
(351.3)\end{array}$ & $\begin{array}{c}3618.9^{* *} \\
(286.0)\end{array}$ \\
\hline $\bar{c}^{s h}$ & & & $\begin{array}{c}-3730.9^{* *} \\
(128.9)\end{array}$ & $\begin{array}{c}-5222.8^{* *} \\
(168.3)\end{array}$ & $\begin{array}{c}-5159.8^{* *} \\
(134.8)\end{array}$ \\
\hline$\omega^{a}$ & $\begin{array}{c}0.0000122 \\
(0.0000249)\end{array}$ & $\begin{array}{l}0.00000753 \\
(0.0000150)\end{array}$ & $\begin{array}{c}0.00186^{*} \\
(0.000910)\end{array}$ & $\begin{array}{c}0.00279^{* *} \\
(0.000953)\end{array}$ & $\begin{array}{c}0.00289^{* *} \\
(0.000946)\end{array}$ \\
\hline$\omega^{m}$ & $\begin{array}{c}0.191^{* *} \\
(0.00432)\end{array}$ & $\begin{array}{c}0.177^{* *} \\
(0.00469)\end{array}$ & $\begin{array}{c}0.216^{* *} \\
(0.00254)\end{array}$ & $\begin{array}{c}0.173^{* *} \\
(0.00430)\end{array}$ & $\begin{array}{c}0.175^{* *} \\
(0.00376)\end{array}$ \\
\hline$\omega^{s}$ & $\begin{array}{c}0.809^{* *} \\
(0.00429)\end{array}$ & $\begin{array}{c}0.823^{* *} \\
(0.00470)\end{array}$ & $\begin{array}{c}0.782^{* *} \\
(0.00280)\end{array}$ & $\begin{array}{c}0.824^{* *} \\
(0.00409)\end{array}$ & $\begin{array}{c}0.822^{* *} \\
(0.00359)\end{array}$ \\
\hline$\psi$ & $\begin{array}{c}0.558^{* *} \\
(0.00359)\end{array}$ & $\begin{array}{c}0.559^{* *} \\
(0.00343)\end{array}$ & $\begin{array}{c}0.613^{* *} \\
(0.00378)\end{array}$ & $\begin{array}{c}0.646^{* *} \\
(0.00662)\end{array}$ & $\begin{array}{c}0.644^{* *} \\
(0.00604)\end{array}$ \\
\hline$N$ & 64 & 64 & 64 & 64 & 64 \\
\hline$A I C$ & -1167.0 & -1159.0 & -1228.1 & -1297.4 & -1299.2 \\
\hline$B I C$ & -1135.4 & -1121.1 & -1190.2 & -1253.2 & -1261.2 \\
\hline$R M S E^{a}$ & 0.004 & 0.004 & 0.004 & 0.004 & 0.004 \\
\hline$R M S E^{m}$ & 0.008 & 0.008 & 0.012 & 0.007 & 0.007 \\
\hline$R M S E^{s m}$ & 0.069 & 0.065 & 0.039 & 0.027 & 0.027 \\
\hline$R M S E^{s h}$ & 0.068 & 0.070 & 0.034 & 0.029 & 0.029 \\
\hline
\end{tabular}

Robust standard errors in parentheses

${ }^{\dagger} p<0.10,{ }^{*} p<0.05,{ }^{* *} p<0.01$

Note: $N$ stands for the number of the sample in the estimation. $A I C$ is Akaike Information Criterion. BIC is Bayesian Information Criterion. $R M S E^{j}$ is the Root Mean Squared Error for $j$-sector's share equation. 
TABle A.2 - Splitting Durable Goods, Case 2: Estimation Results

\begin{tabular}{|c|c|c|c|c|c|}
\hline & $\begin{array}{c}(1) \\
1\end{array}$ & $\begin{array}{c}(2) \\
2\end{array}$ & $\begin{array}{c}(3) \\
3\end{array}$ & $\begin{array}{l}(4) \\
4 a\end{array}$ & $\begin{array}{l}(5) \\
4 b\end{array}$ \\
\hline$\sigma$ & $\begin{array}{l}0.140^{* *} \\
(0.0375)\end{array}$ & $\begin{array}{c}0.0188^{\dagger} \\
(0.0109)\end{array}$ & $\begin{array}{c}0.00163 \\
(0.00115)\end{array}$ & $\begin{array}{l}0.0133^{* *} \\
(0.00404)\end{array}$ & \\
\hline $\bar{c}^{a}$ & $\begin{array}{c}-184.4^{* *} \\
(3.936)\end{array}$ & $\begin{array}{l}-179.9^{* *} \\
(3.351)\end{array}$ & $\begin{array}{l}-150.1^{* *} \\
(9.708)\end{array}$ & $\begin{array}{l}-133.4^{* *} \\
(10.71)\end{array}$ & $\begin{array}{l}-129.8^{* *} \\
(10.64)\end{array}$ \\
\hline $\bar{c}^{s}$ & & $\begin{array}{l}-904.1^{* *} \\
(198.6)\end{array}$ & & $\begin{array}{c}3754.8^{* *} \\
(267.3)\end{array}$ & $\begin{array}{c}3635.2^{* *} \\
(303.2)\end{array}$ \\
\hline $\bar{c}^{s h}$ & & & $\begin{array}{c}-3935.1^{* *} \\
(123.2)\end{array}$ & $\begin{array}{c}-5127.9^{* *} \\
(120.6)\end{array}$ & $\begin{array}{c}-5118.6^{* *} \\
(126.1)\end{array}$ \\
\hline$\omega^{a}$ & $\begin{array}{c}0.0000177 \\
(0.0000269)\end{array}$ & $\begin{array}{c}0.0000114 \\
(0.0000331)\end{array}$ & $\begin{array}{l}0.00221^{*} \\
(0.00102)\end{array}$ & $\begin{array}{c}0.00265^{* *} \\
(0.000932)\end{array}$ & $\begin{array}{c}0.00294^{* *} \\
(0.000881)\end{array}$ \\
\hline$\omega^{m}$ & $\begin{array}{c}0.203^{* *} \\
(0.00544)\end{array}$ & $\begin{array}{c}0.224^{* *} \\
(0.00447)\end{array}$ & $\begin{array}{c}0.233^{* *} \\
(0.00308)\end{array}$ & $\begin{array}{c}0.186^{* *} \\
(0.00384)\end{array}$ & $\begin{array}{c}0.188^{* *} \\
(0.00412)\end{array}$ \\
\hline$\omega^{s}$ & $\begin{array}{c}0.797^{* *} \\
(0.00547)\end{array}$ & $\begin{array}{c}0.776^{* *} \\
(0.00446)\end{array}$ & $\begin{array}{c}0.765^{* *} \\
(0.00280)\end{array}$ & $\begin{array}{c}0.811^{* *} \\
(0.00420)\end{array}$ & $\begin{array}{c}0.809^{* *} \\
(0.00423)\end{array}$ \\
\hline$\psi$ & $\begin{array}{c}0.572^{* *} \\
(0.00238)\end{array}$ & $\begin{array}{c}0.569^{* *} \\
(0.00737)\end{array}$ & $\begin{array}{c}0.634^{* *} \\
(0.00584)\end{array}$ & $\begin{array}{c}0.662^{* *} \\
(0.00527)\end{array}$ & $\begin{array}{c}0.663^{* *} \\
(0.00507)\end{array}$ \\
\hline$N$ & 64 & 64 & 64 & 64 & 64 \\
\hline$A I C$ & -1151.0 & -1153.4 & -1216.7 & -1279.9 & -1281.5 \\
\hline$B I C$ & -1119.4 & -1115.5 & -1178.8 & -1235.6 & -1243.5 \\
\hline$R M S E^{a}$ & 0.005 & 0.004 & 0.004 & 0.004 & 0.004 \\
\hline$R M S E^{m}$ & 0.009 & 0.010 & 0.013 & 0.008 & 0.008 \\
\hline$R M S E^{s m}$ & 0.070 & 0.071 & 0.038 & 0.028 & 0.027 \\
\hline$R M S E^{s h}$ & 0.069 & 0.068 & 0.034 & 0.029 & 0.029 \\
\hline
\end{tabular}

Robust standard errors in parentheses

${ }^{\dagger} p<0.10,{ }^{*} p<0.05,{ }^{* *} p<0.01$

Note: $N$ stands for the number of the sample in the estimation. AIC is Akaike Information Criterion. BIC is Bayesian Information Criterion. $R M S E^{j}$ is the Root Mean Squared Error for $j$-sector's share equation. 
TABLE A.3 - Excluding Government Consumption: Estimation Results

\begin{tabular}{|c|c|c|c|c|c|}
\hline & $\begin{array}{c}(1) \\
1\end{array}$ & $\begin{array}{c}(2) \\
2\end{array}$ & $\begin{array}{c}(3) \\
3\end{array}$ & $\begin{array}{l}(4) \\
4 a\end{array}$ & $\begin{array}{l}(5) \\
4 b\end{array}$ \\
\hline$\sigma$ & $\begin{array}{l}0.275^{* *} \\
(0.0441)\end{array}$ & $\begin{array}{c}0.00131 \\
(0.00118)\end{array}$ & $\begin{array}{c}0.00286 \\
(0.00191)\end{array}$ & $\begin{array}{l}0.00615^{*} \\
(0.00272)\end{array}$ & \\
\hline $\bar{c}^{a}$ & $\begin{array}{l}-155.1^{* *} \\
(3.176)\end{array}$ & $\begin{array}{l}-163.1^{* *} \\
(3.394)\end{array}$ & $\begin{array}{l}-153.5^{* *} \\
(3.356)\end{array}$ & $\begin{array}{c}-121.3^{* *} \\
(11.66)\end{array}$ & $\begin{array}{l}-121.1^{* *} \\
(11.58)\end{array}$ \\
\hline $\bar{c}^{s}$ & & $\begin{array}{l}4478.6^{* *} \\
(308.8)\end{array}$ & & $\begin{array}{c}4136.5^{* *} \\
(235.0)\end{array}$ & $\begin{array}{c}4127.0^{* *} \\
(192.4)\end{array}$ \\
\hline $\bar{c}^{s h}$ & & & $\begin{array}{c}-2144.5^{* *} \\
(196.5)\end{array}$ & $\begin{array}{c}-4694.7^{* *} \\
(174.7)\end{array}$ & $\begin{array}{r}-4706.2^{* *} \\
(141.8)\end{array}$ \\
\hline$\omega^{a}$ & $\begin{array}{c}0.0000147 \\
(0.0000181)\end{array}$ & $\begin{array}{c}0.0000134 \\
(0.0000259)\end{array}$ & $\begin{array}{c}0.00000766 \\
(0.0000138)\end{array}$ & $\begin{array}{l}0.00245^{*} \\
(0.00111)\end{array}$ & $\begin{array}{c}0.00243^{*} \\
(0.00112)\end{array}$ \\
\hline$\omega^{m}$ & $\begin{array}{c}0.164^{* *} \\
(0.00362)\end{array}$ & $\begin{array}{c}0.134^{* *} \\
(0.00308)\end{array}$ & $\begin{array}{c}0.198^{* *} \\
(0.00288)\end{array}$ & $\begin{array}{c}0.154^{* *} \\
(0.00308)\end{array}$ & $\begin{array}{c}0.155^{* *} \\
(0.00299)\end{array}$ \\
\hline$\omega^{s}$ & $\begin{array}{c}0.836^{* *} \\
(0.00361)\end{array}$ & $\begin{array}{c}0.866^{* *} \\
(0.00309)\end{array}$ & $\begin{array}{c}0.802^{* *} \\
(0.00288)\end{array}$ & $\begin{array}{c}0.843^{* *} \\
(0.00342)\end{array}$ & $\begin{array}{c}0.843^{* *} \\
(0.00373)\end{array}$ \\
\hline$\psi$ & $\begin{array}{c}0.527^{* *} \\
(0.00244)\end{array}$ & $\begin{array}{c}0.531^{* *} \\
(0.00300)\end{array}$ & $\begin{array}{c}0.553^{* *} \\
(0.00345)\end{array}$ & $\begin{array}{c}0.596^{* *} \\
(0.00462)\end{array}$ & $\begin{array}{c}0.596^{* *} \\
(0.00331)\end{array}$ \\
\hline$N$ & 64 & 64 & 64 & 64 & 64 \\
\hline$A I C$ & -1210.6 & -1212.8 & -1208.5 & -1330.3 & -1332.1 \\
\hline$B I C$ & -1179.1 & -1174.9 & -1170.6 & -1286.0 & -1294.2 \\
\hline$R M S E^{a}$ & 0.004 & 0.005 & 0.004 & 0.004 & 0.004 \\
\hline$R M S E^{m}$ & 0.010 & 0.009 & 0.011 & 0.006 & 0.006 \\
\hline$R M S E^{s m}$ & 0.061 & 0.053 & 0.046 & 0.027 & 0.027 \\
\hline$R M S E^{s h}$ & 0.057 & 0.064 & 0.042 & 0.032 & 0.032 \\
\hline
\end{tabular}

Robust standard errors in parentheses

${ }^{\dagger} p<0.10,{ }^{*} p<0.05,{ }^{* *} p<0.01$

Note: $N$ stands for the number of the sample in the estimation. AIC is Akaike Information Criterion. BIC is Bayesian Information Criterion. $R M S E^{j}$ is the Root Mean Squared Error for $j$-sector's share equation. 


\section{B Derivation of Sectoral Share Equations}

\section{B.1 Benchmark Case}

The Lagrangian for household's maximization problem (P3) is written as:

$$
\mathcal{L}=\left(\sum_{i=a, m, s}\left(\omega^{i}\right)^{\frac{1}{\sigma}}\left(c_{t}^{i}+\bar{c}^{i}\right)^{\frac{\sigma-1}{\sigma}}\right)^{\frac{\sigma}{\sigma-1}}+\lambda_{t}\left[E_{t}-p_{t}^{a} c_{t}^{a}-p_{t}^{m} c_{t}^{m}-p_{t}^{s m} c_{t}^{s m}-p_{t}^{s h} c_{t}^{s h}\right],
$$

where

$$
c_{t}^{s}=\left[\psi\left(c_{t}^{s m}\right)^{\frac{\gamma-1}{\gamma}}+(1-\psi)\left(c_{t}^{s h}+\bar{c}^{s h}\right)^{\frac{\gamma-1}{\gamma}}\right]^{\frac{\gamma}{\gamma-1}} .
$$

The first order conditions are;

$$
\begin{aligned}
& \frac{\partial \mathcal{L}}{\partial c_{t}^{a}}=0 \Longrightarrow\left(\omega^{a}\right)^{1 / \sigma}\left(c_{t}^{a}+\bar{c}^{a}\right)^{\frac{-1}{\sigma}}\left(\Psi_{t}\right)^{\frac{1}{\sigma-1}}=\lambda_{t} p_{t}^{a}, \\
& \frac{\partial \mathcal{L}}{\partial c_{t}^{m}}=0 \Longrightarrow\left(\omega^{m}\right)^{1 / \sigma}\left(c_{t}^{m}+\bar{c}^{m}\right)^{\frac{-1}{\sigma}}\left(\Psi_{t}\right)^{\frac{1}{\sigma-1}}=\lambda_{t} p_{t}^{m}, \\
& \frac{\partial \mathcal{L}}{\partial c_{t}^{s m}}=0 \Longrightarrow\left(\omega^{s}\right)^{1 / \sigma} \psi\left(c_{t}^{s m}\right)^{\frac{-1}{\gamma}}\left(c_{t}^{s}\right)^{\frac{1}{\gamma}}\left(c_{t}^{s}+\bar{c}^{s}\right)^{\frac{-1}{\sigma}}\left(\Psi_{t}\right)^{\frac{1}{\sigma-1}}=\lambda_{t} p_{t}^{s m}, \\
& \frac{\partial \mathcal{L}}{\partial c_{t}^{s h}}=0 \Longrightarrow\left(\omega^{s}\right)^{1 / \sigma}(1-\psi)\left(c_{t}^{s h}+\bar{c}^{s h}\right)^{\frac{-1}{\gamma}}\left(c_{t}^{s}\right)^{\frac{1}{\gamma}}\left(c_{t}^{s}+\bar{c}^{s}\right)^{\frac{-1}{\sigma}}\left(\Psi_{t}\right)^{\frac{1}{\sigma-1}}=\lambda_{t} p_{t}^{s h},
\end{aligned}
$$

where

$$
\Psi_{t} \equiv\left(\omega^{a}\right)^{1 / \sigma}\left(c_{t}^{a}+\bar{c}^{a}\right)^{\frac{\sigma-1}{\sigma}}+\left(\omega^{m}\right)^{1 / \sigma}\left(c_{t}^{m}+\bar{c}^{m}\right)^{\frac{\sigma-1}{\sigma}}+\left(\omega^{s}\right)^{1 / \sigma}\left(c_{t}^{s}+\bar{c}^{s}\right)^{\frac{\sigma-1}{\sigma}} .
$$

From the first order conditions, we can derive the following share equations;

$$
\begin{aligned}
\frac{p_{t}^{a} c_{t}^{a}}{E_{t}} & =f_{1} \equiv \frac{\left(p_{t}^{a}\right)^{1-\sigma} \omega^{a} \Phi_{t, 1}}{\Phi_{t, 2}}-\frac{p_{t}^{a} \bar{c}_{t}^{a}}{E_{t}} \\
\frac{p_{t}^{m} c_{t}^{m}}{E_{t}} & =f_{2} \equiv \frac{\left(p_{t}^{m}\right)^{1-\sigma} \omega^{m} \Phi_{t, 1}}{\Phi_{t, 2}}-\frac{p_{t}^{m} \bar{c}_{t} m}{E_{t}} \\
\frac{p_{t}^{s m} c_{t}^{s m}}{E_{t}} & =f_{3} \equiv \frac{\left(p_{t}^{s m}\right)^{1-\sigma} \omega^{s} \psi^{\sigma} \Omega_{t, 1}^{\frac{\sigma}{\gamma}-1} \Phi_{t, 1}}{\Phi_{t, 2}}-\frac{p_{t}^{s m} \Omega_{t, 1}^{-1} \bar{c}^{s}}{E_{t}}
\end{aligned}
$$

where

$$
\begin{aligned}
& \Phi_{t, 1} \equiv\left(1+\frac{p_{t}^{a} \bar{c}^{a}+p_{t}^{m} \bar{c}^{m}+p_{t}^{s h} \bar{c}^{s h}+p_{t}^{s m} \Omega_{t, 1}^{-1} \bar{c}^{s}+p_{t}^{s h} \Omega_{t, 2}^{-1} \bar{c}^{s}}{E}\right), \\
& \Phi_{t, 2} \equiv\left(p_{t}^{a}\right)^{1-\sigma} \omega^{a}+\left(p_{t}^{m}\right)^{1-\sigma} \omega^{m}+\left(p_{t}^{s m}\right)^{1-\sigma} \omega^{s} \psi^{\sigma} \Omega_{t, 1}^{\frac{\sigma}{\gamma}-1}+\left(p_{t}^{s h}\right)^{1-\sigma} \omega^{s}(1-\psi)^{\sigma} \Omega_{t, 2}^{\frac{\sigma}{\gamma}-1},
\end{aligned}
$$


and where

$$
\begin{aligned}
& \Omega_{t, 1} \equiv\left[\psi+(1-\psi)\left(\frac{1-\psi}{\psi}\right)^{\gamma-1}\left(\frac{p_{t}^{s m}}{p_{t}^{s h}}\right)^{\gamma-1}\right]^{\frac{\gamma}{\gamma-1}}, \\
& \Omega_{t, 2} \equiv\left[\psi\left(\frac{\psi}{1-\psi}\right)^{\gamma-1}\left(\frac{p_{t}^{s h}}{p_{t}^{s m}}\right)^{\gamma-1}+(1-\psi)\right]^{\frac{\gamma}{\gamma-1}} .
\end{aligned}
$$

The share equations, (8), (9), and (10) are used for estimation.

\section{B.2 Disaggregated Case}

The Lagrangian for household problem is

$$
\mathcal{L}=\left(\sum_{i=a, m, s n, s c}\left(\omega^{i}\right)^{\frac{1}{\sigma}}\left(c_{t}^{i}+\bar{c}^{i}\right)^{\frac{\sigma-1}{\sigma}}\right)^{\frac{\sigma}{\sigma-1}}+\lambda\left[E-p_{t}^{a} c_{t}^{a}-p_{t}^{m} c_{t}^{m}-p_{t}^{s n} c_{t}^{s n}-p_{t}^{s m} c_{t}^{s m}-p_{t}^{s h} c_{t}^{s h}\right],
$$

where

$$
c_{t}^{s c}=\left[\psi\left(c_{t}^{s m}\right)^{\frac{\gamma-1}{\gamma}}+(1-\psi)\left(c_{t}^{s h}+\bar{c}^{s h}\right)^{\frac{\gamma-1}{\gamma}}\right]^{\frac{\gamma}{\gamma-1}} .
$$

From FOCs we can derive the share equations

$$
\begin{aligned}
\frac{p_{t}^{a} c_{t}^{a}}{E_{t}} & =g_{1} \equiv \frac{\left(p_{t}^{a}\right)^{1-\sigma} \omega^{a} \Psi_{t, 1}}{\Psi_{t, 2}}-\frac{p_{t}^{a} \bar{c}^{a}}{E_{t}}, \\
\frac{p_{t}^{m} c_{t}^{m}}{E_{t}} & =g_{2} \equiv \frac{\left(p_{t}^{m}\right)^{1-\sigma} \omega^{m} \Psi_{t, 1}}{\Psi_{t, 2}}-\frac{p_{t}^{m} \bar{c}^{m}}{E_{t}}, \\
\frac{p_{t}^{s n} c_{t}^{s n}}{E_{t}} & =g_{3} \equiv \frac{\left(p_{t}^{s n}\right)^{1-\sigma} \omega^{s n} \Psi_{t, 1}}{\Psi_{t, 2}}-\frac{p_{t}^{s n} \bar{c}^{s n}}{E_{t}}, \\
\frac{p_{t}^{s m} c_{t}^{s m}}{E_{t}} & =g_{4} \equiv \frac{\left(p_{t}^{s m}\right)^{1-\sigma} \omega^{s c} \psi^{\sigma} \Gamma_{t, 1}^{\frac{\sigma}{\gamma}-1} \Psi_{t, 1}}{\Psi_{t, 2}}-\frac{p_{t}^{s m} \Gamma_{t, 1}^{-1} \bar{c}^{s c}}{E_{t}} .
\end{aligned}
$$

where

$\Psi_{t, 1} \equiv\left(1+\frac{p_{t}^{a} \bar{c}^{a}+p_{t}^{m} \bar{c}^{m}+p_{t}^{s n} \bar{c}^{s n}+p_{t}^{s h} \bar{c}^{s h}+p_{t}^{s m} \Gamma_{t, 1}^{-1} \bar{c}^{s c}+p_{t}^{s h} \Gamma_{t, 2}^{-1} \bar{c}^{s c}}{E_{t}}\right)$,

$\Psi_{t, 2} \equiv\left(p_{t}^{a}\right)^{1-\sigma} \omega^{a}+\left(p_{t}^{m}\right)^{1-\sigma} \omega^{m}+\left(p_{t}^{s n}\right)^{1-\sigma} \omega^{s n}+\left(p_{t}^{s m}\right)^{1-\sigma} \omega^{s c} \psi^{\sigma} \Gamma_{t, 1}^{\frac{\sigma}{\gamma}-1}+\left(p_{t}^{s h}\right)^{1-\sigma} \omega^{s c}(1-\psi)^{\sigma} \Gamma_{t, 2}^{\frac{\sigma}{\gamma}-1}$,

and where

$$
\begin{aligned}
\Gamma_{t, 1} & \equiv\left[\psi+(1-\psi)\left(\frac{1-\psi}{\psi}\right)^{\gamma-1}\left(\frac{p_{t}^{s m}}{p_{t}^{s h}}\right)^{\gamma-1}\right]^{\frac{\gamma}{\gamma-1}} \\
\Gamma_{t, 2} & \equiv\left[\psi\left(\frac{\psi}{1-\psi}\right)^{\gamma-1}\left(\frac{p_{t}^{s h}}{p_{t}^{s m}}\right)^{\gamma-1}+(1-\psi)\right]^{\frac{\gamma}{\gamma-1}}
\end{aligned}
$$


Supplemental Online Appendix 


\section{Online Appendix}

\section{A Separating Inter- and Intra-Temporal Problems}

In this appendix, we show how to separate the inter-temporal problem, in which the household decides aggregate consumption and investment across time, from the intra-temporal one, in which the household decides consumption levels of the four goods, given resources allocated to consumption in that period. We re-write here the household equivalent problem (P1):

$$
\max \sum_{t=0}^{\infty} \beta^{t} \ln C_{t}
$$

subject to

$$
\begin{gathered}
C_{t}=\left(\sum_{i=a, m, s}\left(\omega^{i}\right)^{\frac{1}{\sigma}}\left(c_{t}^{i}+\bar{c}^{i}\right)^{\frac{\sigma-1}{\sigma}}\right)^{\frac{\sigma}{\sigma-1}}, \\
c_{t}^{s}=\left[\psi\left(c_{t}^{s m}\right)^{\frac{\gamma-1}{\gamma}}+(1-\psi)\left(c_{t}^{s h}+\bar{c}^{s h}\right)^{\frac{\gamma-1}{\gamma}}\right]^{\frac{\gamma}{\gamma-1}}, \\
p_{t}^{a} c_{t}^{a}+p_{t}^{m} c_{t}^{m}+p_{t}^{s m} c_{t}^{s m}+p_{t}^{s h} c_{t}^{s h}+k_{t+1}-(1-\delta) k_{t}=r_{t} k_{t}+w_{t} \bar{l},
\end{gathered}
$$

The first order conditions for the four consumption goods are

$$
\begin{aligned}
\frac{\partial \mathcal{L}}{\partial c_{t}^{a}} & =0 \Longrightarrow \frac{\beta^{t}\left(\omega^{a}\right)^{1 / \sigma}\left(c_{t}^{a}+\bar{c}^{a}\right)^{\frac{-1}{\sigma}}\left(C_{t}\right)^{\frac{1}{\sigma}}}{C_{t}}=\lambda_{t} p_{t}^{a} \\
\frac{\partial \mathcal{L}}{\partial c_{t}^{m}} & =0 \Longrightarrow \frac{\beta^{t}\left(\omega^{m}\right)^{1 / \sigma}\left(c_{t}^{m}+\bar{c}^{m}\right)^{\frac{-1}{\sigma}}\left(C_{t}\right)^{\frac{1}{\sigma}}}{C_{t}}=\lambda_{t} p_{t}^{m} \\
\frac{\partial \mathcal{L}}{\partial c_{t}^{s m}} & =0 \Longrightarrow \frac{\beta^{t}\left(\omega^{s}\right)^{1 / \sigma} \psi\left(c_{t}^{s m}\right)^{\frac{-1}{\gamma}}\left(c_{t}^{s}\right)^{\frac{1}{\gamma}}\left(c_{t}^{s}+\bar{c}^{s}\right)^{\frac{-1}{\sigma}}\left(C_{t}\right)^{\frac{1}{\sigma}}}{C_{t}}=\lambda_{t} p_{t}^{s m} \\
\frac{\partial \mathcal{L}}{\partial c_{t}^{s h}} & =0 \Longrightarrow \frac{\beta^{t}\left(\omega^{s}\right)^{1 / \sigma}(1-\psi)\left(c_{t}^{s h}+\bar{c}^{s h}\right)^{\frac{-1}{\gamma}}\left(c_{t}^{s}\right)^{\frac{1}{\gamma}}\left(c_{t}^{s}+\bar{c}^{s}\right)^{\frac{-1}{\sigma}}\left(C_{t}\right)^{\frac{1}{\sigma}}}{C_{t}}=\lambda_{t} p_{t}^{s h}
\end{aligned}
$$

Raise (17) and (18) to $1-\gamma$, sum them and raise to $\frac{1}{1-\gamma}$ to obtain

$$
\frac{\beta^{t}\left(\omega^{s}\right)^{1 / \sigma}\left(c_{t}^{s}+\bar{c}^{s}\right)^{\frac{-1}{\sigma}}\left(C_{t}\right)^{\frac{1}{\sigma}}}{C_{t}}=\lambda_{t}\left[\left(p_{t}^{s m}\right)^{1-\gamma} \psi^{\gamma}+\left(p_{t}^{s h}\right)^{1-\gamma}(1-\psi)^{\gamma}\right]^{\frac{1}{1-\gamma}}
$$

As $\lambda_{t}$ is the marginal utility of one additional unit of good $i$ divided by the price of that good, we can define

$$
p_{t}^{s} \equiv\left[\psi^{\gamma}\left(p_{t}^{s m}\right)^{1-\gamma}+(1-\psi)^{\gamma}\left(p_{t}^{s h}\right)^{1-\gamma}\right]^{\frac{1}{1-\gamma}},
$$

that is, one unit of the services consumption bundle costs $p_{t}^{s}$. Note that by using (20) we can write

$$
\frac{\beta^{t}\left(\omega^{s}\right)^{1 / \sigma}\left(c_{t}^{s}+\bar{c}^{s}\right)^{\frac{-1}{\sigma}}\left(C_{t}\right)^{\frac{1}{\sigma}}}{C_{t}}=\lambda_{t} p_{t}^{s} .
$$


Now sum FOCs (15) and (16) and use the definition of $p_{t}^{s}$ to obtain

$$
\frac{\beta^{t}\left(\omega^{s}\right)^{1 / \sigma}\left(c_{t}^{s}+\bar{c}^{s}\right)^{\frac{-1}{\sigma}}\left(C_{t}\right)^{\frac{1}{\sigma}}}{C_{t}} c_{t}^{s}=\lambda_{t}\left[p_{t}^{s m} c_{t}^{s m}+p_{t}^{s h} c_{t}^{s h}+p_{t}^{s h} \bar{c}^{s h}\right]
$$

Recall now from (21) that

$$
\frac{\beta^{t}\left(\omega^{s}\right)^{1 / \sigma}\left(c_{t}^{s}+\bar{c}^{s}\right)^{\frac{-1}{\sigma}}\left(C_{t}\right)^{\frac{1}{\sigma}}}{p_{t}^{s} C_{t}}=\lambda_{t},
$$

so we can use the last expression in (22) to obtain

$$
p_{t}^{s} c_{t}^{s}-p_{t}^{s h} \bar{c}^{s h}=p_{t}^{s m} c_{t}^{s m}+p_{t}^{s h} c_{t}^{s h} .
$$

Now raise each condition (15), (16) and (21) to $1-\sigma$ and sum across conditions

$$
\frac{\beta^{t(1-\sigma)} C_{t}^{\frac{1-\sigma}{\sigma}}}{C_{t}^{1-\sigma}}\left[\sum_{i=a, m, s}\left(\omega^{i}\right)^{\frac{1}{\sigma}}\left(c_{t}^{i}+\bar{c}^{i}\right)^{\frac{\sigma-1}{\sigma}}\right]=\lambda_{t}^{1-\sigma}\left[\sum_{i=a, m, s} \omega^{i}\left(p_{t}^{i}\right)^{1-\sigma}\right],
$$

raise to $\frac{1}{1-\sigma}$ and simplify to obtain

$$
\frac{\beta^{t}}{C_{t}}=\lambda_{t}\left[\sum_{i=a, m, s} \omega^{i}\left(p_{t}^{i}\right)^{1-\sigma}\right]^{\frac{1}{1-\sigma}}
$$

As $\lambda_{t}$ is the marginal utility of one additional unit of the consumption aggregator $C_{t}$ in units of that good, and $\frac{\beta^{t}}{C_{t}}$ is the marginal utility of consumption, we can define the implicit price index $P_{t}$ as

$$
P_{t} \equiv\left[\sum_{i=a, m, s} \omega^{i}\left(p_{t}^{i}\right)^{1-\sigma}\right]^{\frac{1}{1-\sigma}}
$$

Now sum across conditions (15), (16) and (21) to obtain

$$
P_{t} C_{t}=\sum_{i=a, m, s} p_{t}^{i} c_{t}^{i}+\sum_{i=a, m, s} p_{t}^{i} \bar{c}^{i} .
$$

Use (23) to substitute for $p_{t}^{s m} c_{t}^{s m}+p_{t}^{s h} c_{t}^{s h}$ in the budget constraint of the household to obtain

$$
p_{t}^{a} c_{t}^{a}+p_{t}^{m} c_{t}^{m}+p_{t}^{s} c_{t}^{s}+k_{t+1}-(1-\delta) k_{t}=r_{t} k_{t}+w_{t} \bar{l}+p_{t}^{s h} \bar{c}^{s h}
$$

and use (24) to substitute for $p_{t}^{a} c_{t}^{a}+p_{t}^{m} c_{t}^{m}+p_{t}^{s} c_{t}^{s}$ to obtain

$$
P_{t} C_{t}+k_{t+1}-(1-\delta) k_{t}=r_{t} k_{t}+w_{t} \bar{l}+p_{t}^{s h} \bar{c}^{s h}+\sum_{i=a, m, s} p_{t}^{i} \bar{c}^{i} .
$$

We are now equipped to state the inter-temporal and the intra-temporal problems:

1. Inter-Temporal Problem: The household solves:

$$
\max _{\left\{C_{t}, k_{t+1}\right\}} \sum_{t=0}^{\infty} \beta^{t} \ln C_{t}
$$


subject to

$$
P_{t} C_{t}+k_{t+1}-(1-\delta) k_{t}=r_{t} k_{t}+w_{t} \bar{l}+p_{t}^{s h} \bar{c}^{s h}+\sum_{i=a, m, s} p_{t}^{i} \bar{c}^{i}
$$

2. Intra-Temporal Problem: The household solves:

$$
\max _{\left\{c_{t}^{a}, c_{t}^{m}, c_{t}^{s m}, c_{t}^{s h}\right\}}\left(\sum_{i=a, m, s}\left(\omega^{i}\right)^{\frac{1}{\sigma}}\left(c_{t}^{i}+\bar{c}^{i}\right)^{\frac{\sigma-1}{\sigma}}\right)^{\frac{\sigma}{\sigma-1}}
$$

subject to

$$
c_{t}^{s}=\left[\psi\left(c_{t}^{s m}\right)^{\frac{\gamma-1}{\gamma}}+(1-\psi)\left(c_{t}^{s h}+\bar{c}^{s h}\right)^{\frac{\gamma-1}{\gamma}}\right]^{\frac{\gamma}{\gamma-1}},
$$

and

$$
p_{t}^{a} c_{t}^{a}+p_{t}^{m} c_{t}^{m}+p_{t}^{s m} c_{t}^{s m}+p_{t}^{s h} c_{t}^{s h}=P_{t} C_{t}-\sum_{i=a, m, s} p_{t}^{i} \bar{c}^{i}-p_{t}^{s h} \bar{c}^{s h}
$$

Thus, the problems (P1) is decomposed into (P2) and (P3). 


\section{B Elasticity of Substitution Parameter}

In this appendix, we run two robustness checks on the elasticity of substitution parameter $\gamma$. First, we run the estimation by setting the parameter $\gamma$ equal to 1.5 , the lowest value estimated in the previous literature. Second, we estimate the parameter $\gamma$ together with the rest of the parameters. In both cases, the main results of the estimation are close to benchmark.

\section{Setting $\gamma$ Equal to 1.5}

In the benchmark estimation, we set the substitutability parameter $\gamma$ equal to 2.3 , the highest value among the range of the estimates in the previous literature. As we discussed before, we do so, because these estimates correspond to the elasticity of substitution between all market and nonmarket goods. Instead, in our model we consider the substitutability between market services and non-market services (home production). Since market services are likely to be more substitutable with home production than other types of goods, we pick the highest value for the parameter in the benchmark estimation.

Here we set the parameter $\gamma$ to 1.5, the lowest value estimated in the previous literature, and re-run the estimations. Table OA.1 and Figure OA.1, OA.2, and OA.3 present the estimation results. The model's fit for market and home services is only slightly worse than in the benchmark case. ${ }^{33}$ However, almost all of the main results are preserved. In particular, our finding that the non-homotheticity parameter $\bar{c}^{s h}$ significantly improves the model's performance does not change.

\section{Estimation without Restricting $\gamma$}

Here, instead of fixing the value of $\gamma$, we estimate it together with the rest of the parameters. Table OA.2 and Figures OA.4, OA.5, and OA.6 show the results. Note that, even when we unrestrict the value of $\gamma$, the estimation delivers results which are close to the benchmark case. One issue that arises, however, is that the estimated value of $\gamma$ is high compared to the values documented in the literature. In Model 3, the estimated value of $\gamma$ is 5.7, while, in Models $4 \mathrm{a}$ and $4 \mathrm{~b}$, the values are around 6.9. These numbers are beyond the range of 1.5 to 2.3 found in previous empirical studies.

One possible reason for the high value of $\gamma$ is that the model overfits the market and the home service shares. To see this point, note that when we do not restrict the value of $\gamma$, the model's fit improves significantly, especially for market and home services. The Root Mean Squared Errors $\left(R M S E^{j}\right)$ of Model 4b for market and home services in Table OA.2 decreases by more than $40 \%$ from the values in Table 1. Furthermore, by looking into Figure OA.6, note that the model even tries to fit to the drop of market services and the rise of home services observed in the late 1970s. Indeed, these changes in the late 1970s are the data variations, which generate the high value of the estimate of $\gamma$. When we drop the observations from 1975 to 1979, and run the estimation again, we find that the estimated values of the parameter $\gamma$ falls to 1.1 for Model 4 a and 1.0 for Model 4b, while the other parameter values (especially for $\sigma$ ) do not change significantly. Since the number of our observations is relatively small (64 observations) and changes in prices and shares in the data are in general moderate, there is a possibility that the model overfits a specific data variation, which has relatively large magnitude, by adjusting the elasticity parameter. As we are interested in the model's ability to account for long run trends rather than short run fluctuations, we decided to fix the value of the parameter $\gamma$ in the benchmark estimation to avoid the possibility of the overfitting.

\footnotetext{
${ }^{33}$ Table OA.1 shows that the values of the Root Mean Squared Error (RMSE) for market and home services became higher than those in in Table 1.
} 
TABLE OA.1 - Setting $\gamma$ Equal to 1.5: Estimation Results

\begin{tabular}{|c|c|c|c|c|c|}
\hline & $\begin{array}{c}(1) \\
1\end{array}$ & $\begin{array}{c}(2) \\
2\end{array}$ & $\begin{array}{c}(3) \\
3\end{array}$ & $\begin{array}{l}(4) \\
4 a\end{array}$ & $\begin{array}{l}(5) \\
4 b\end{array}$ \\
\hline$\sigma$ & $\begin{array}{c}0.134^{*} \\
(0.0518)\end{array}$ & $\begin{array}{c}0.0162^{\dagger} \\
(0.00946)\end{array}$ & $\begin{array}{l}0.000519^{*} \\
(0.000231)\end{array}$ & $\begin{array}{l}0.00419^{* *} \\
(0.00149)\end{array}$ & \\
\hline $\bar{c}^{a}$ & $\begin{array}{l}-173.6^{* *} \\
(3.626)\end{array}$ & $\begin{array}{l}-177.0^{* *} \\
(3.295)\end{array}$ & $\begin{array}{l}-156.0^{* *} \\
(10.25)\end{array}$ & $\begin{array}{c}-125.7^{* *} \\
(13.96)\end{array}$ & $\begin{array}{c}-128.7^{* *} \\
(10.81)\end{array}$ \\
\hline $\bar{c}^{s}$ & & $\begin{array}{c}1401.2^{* *} \\
(276.1)\end{array}$ & & $\begin{array}{c}4376.9^{* *} \\
(378.0)\end{array}$ & $\begin{array}{c}4384.8^{* *} \\
(359.8)\end{array}$ \\
\hline $\bar{c}^{s h}$ & & & $\begin{array}{c}-2588.1^{* *} \\
(182.3)\end{array}$ & $\begin{array}{c}-4869.0^{* *} \\
(185.8)\end{array}$ & $\begin{array}{c}-4840.4^{* *} \\
(168.1)\end{array}$ \\
\hline$\omega^{a}$ & $\begin{array}{c}0.0000131 \\
(0.0000294)\end{array}$ & $\begin{array}{c}0.0000213 \\
(0.0000397)\end{array}$ & $\begin{array}{c}0.00119 \\
(0.000991)\end{array}$ & $\begin{array}{l}0.00281^{* *} \\
(0.00108)\end{array}$ & $\begin{array}{l}0.00258^{* *} \\
(0.000814)\end{array}$ \\
\hline$\omega^{m}$ & $\begin{array}{c}0.174^{* *} \\
(0.00296)\end{array}$ & $\begin{array}{c}0.166^{* *} \\
(0.00695)\end{array}$ & $\begin{array}{c}0.194^{* *} \\
(0.00239)\end{array}$ & $\begin{array}{c}0.153^{* *} \\
(0.00380)\end{array}$ & $\begin{array}{c}0.153^{* *} \\
(0.00369)\end{array}$ \\
\hline$\omega^{s}$ & $\begin{array}{c}0.826^{* *} \\
(0.00295)\end{array}$ & $\begin{array}{c}0.834^{* *} \\
(0.00692)\end{array}$ & $\begin{array}{c}0.805^{* *} \\
(0.00249)\end{array}$ & $\begin{array}{c}0.844^{* *} \\
(0.00379)\end{array}$ & $\begin{array}{c}0.844^{* *} \\
(0.00382)\end{array}$ \\
\hline$\psi$ & $\begin{array}{c}0.571^{* *} \\
(0.00381)\end{array}$ & $\begin{array}{c}0.575^{* *} \\
(0.00643)\end{array}$ & $\begin{array}{c}0.621^{* *} \\
(0.00715)\end{array}$ & $\begin{array}{c}0.678^{* *} \\
(0.00843)\end{array}$ & $\begin{array}{c}0.677^{* *} \\
(0.00706)\end{array}$ \\
\hline$N$ & 64 & 64 & 64 & 64 & 64 \\
\hline$A I C$ & -1199.7 & -1191.2 & -1220.1 & -1284.9 & -1287.0 \\
\hline$B I C$ & -1168.1 & -1153.3 & -1182.2 & -1240.7 & -1249.1 \\
\hline$R M S E^{a}$ & 0.004 & 0.004 & 0.004 & 0.004 & 0.004 \\
\hline$R M S E^{m}$ & 0.010 & 0.007 & 0.011 & 0.007 & 0.007 \\
\hline$R M S E^{s m}$ & 0.063 & 0.059 & 0.045 & 0.030 & 0.030 \\
\hline$R M S E^{s h}$ & 0.060 & 0.062 & 0.041 & 0.032 & 0.032 \\
\hline
\end{tabular}

Robust standard errors in parentheses

${ }^{\dagger} p<0.10,{ }^{*} p<0.05,{ }^{* *} p<0.01$

Note: $N$ stands for the number of the sample in the estimation. AIC is Akaike Information Criterion. BIC is Bayesian Information Criterion. $R M S E^{j}$ is the Root Mean Squared Error for $j$-sector's share equation. 
Figure OA.1 - Setting $\gamma$ Equal to 1.5: Model $1\left(\bar{c}^{s}=\bar{c}^{s h}=0\right)$ and Model $2\left(\bar{c}^{s h}=0\right)$
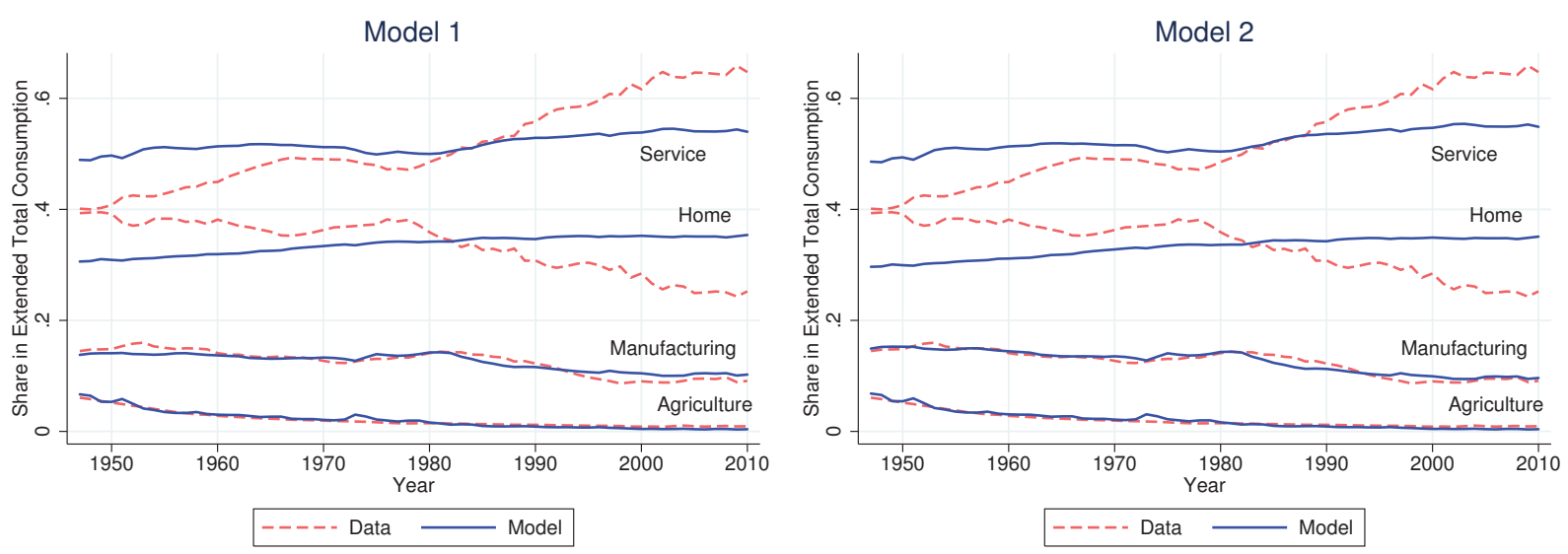

Figure OA.2 - Setting $\gamma$ Equal to 1.5: Model $3\left(\bar{c}^{s}=0\right)$ and Model 4a (no restrictions)

Model 3

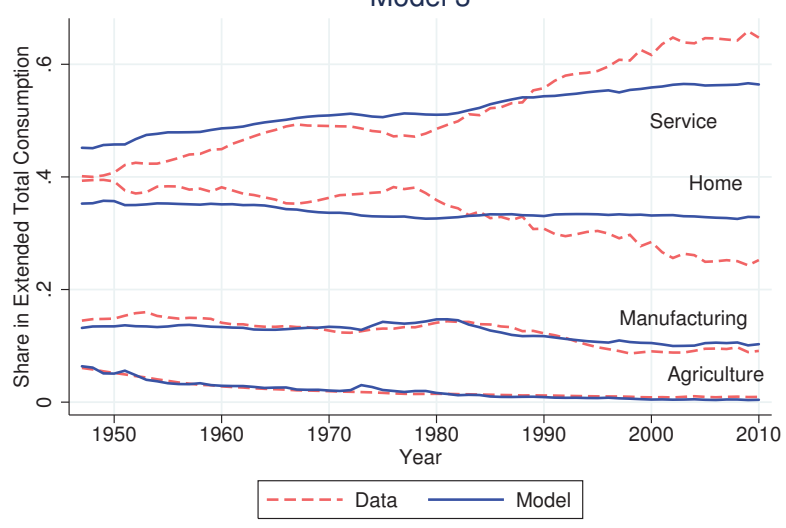

Model $4 a$

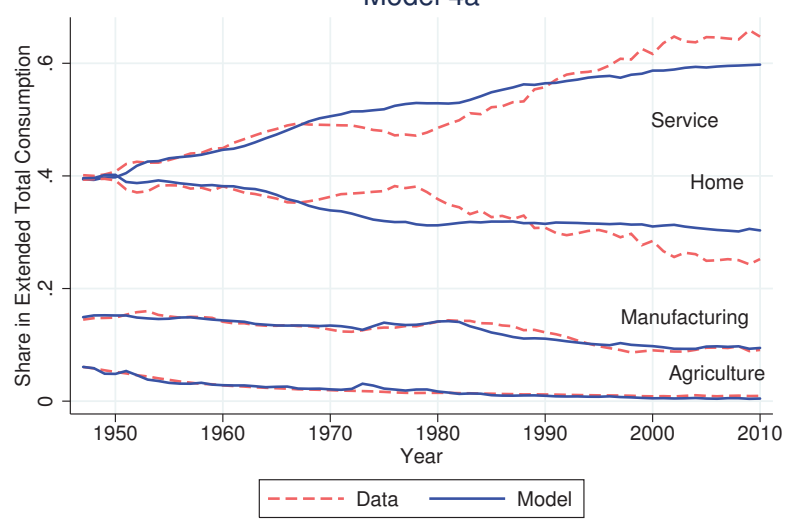

Figure OA.3 - Setting $\gamma$ Equal to 1.5: Model 4b $(\sigma=0)$

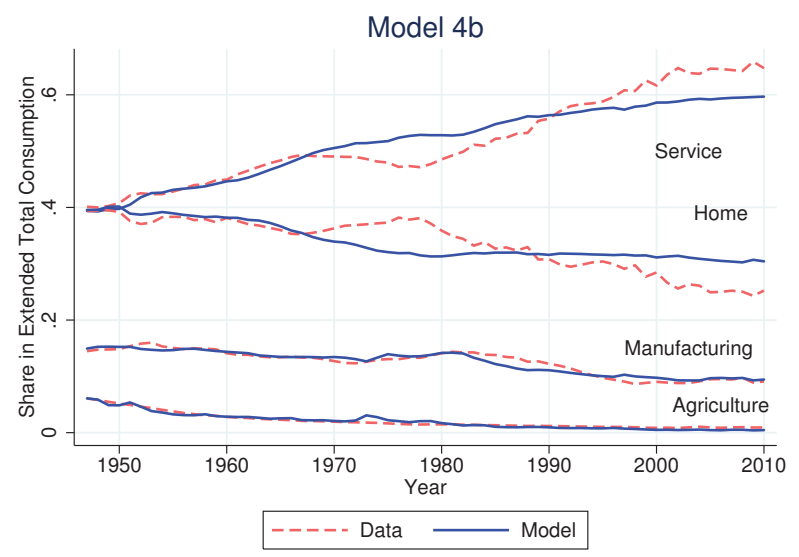


TABLE OA.2 - No Restriction on $\gamma$ : Estimation Results

\begin{tabular}{|c|c|c|c|c|c|}
\hline & $\begin{array}{c}(1) \\
1\end{array}$ & $\begin{array}{c}(2) \\
2\end{array}$ & $\begin{array}{c}(3) \\
3\end{array}$ & $\begin{array}{l}\text { (4) } \\
4 \mathrm{a}\end{array}$ & $\begin{array}{l}\text { (5) } \\
4 \mathrm{~b}\end{array}$ \\
\hline$\sigma$ & $\begin{array}{l}0.0224^{*} \\
(0.0101)\end{array}$ & $\begin{array}{c}0.00312^{\dagger} \\
(0.00185)\end{array}$ & $\begin{array}{c}0.0000971^{\dagger} \\
(0.0000556)\end{array}$ & $\begin{array}{l}0.0215^{* *} \\
(0.00681)\end{array}$ & \\
\hline $\bar{c}^{a}$ & $\begin{array}{c}-170.5^{* *} \\
(3.415)\end{array}$ & $\begin{array}{c}-171.6^{* *} \\
(3.618)\end{array}$ & $\begin{array}{c}-132.8^{* *} \\
(8.631)\end{array}$ & $\begin{array}{c}-122.4^{* *} \\
(10.55)\end{array}$ & $\begin{array}{c}-120.2^{* *} \\
(8.291)\end{array}$ \\
\hline $\bar{c}^{s}$ & & $\begin{array}{l}413.6^{* *} \\
(98.23)\end{array}$ & & $\begin{array}{c}5086.4^{* *} \\
(352.3)\end{array}$ & $\begin{array}{c}4883.4^{* *} \\
(261.4)\end{array}$ \\
\hline $\bar{c}^{s h}$ & & & $\begin{array}{c}-5796.2^{* *} \\
(109.4)\end{array}$ & $\begin{array}{c}-6421.7^{* *} \\
(96.94)\end{array}$ & $\begin{array}{c}-6414.8^{* *} \\
(103.9)\end{array}$ \\
\hline$\omega^{a}$ & $\begin{array}{c}0.0000373 \\
(0.0000731)\end{array}$ & $\begin{array}{c}0.0000300 \\
(0.0000625)\end{array}$ & $\begin{array}{l}0.00333^{* *} \\
(0.00109)\end{array}$ & $\begin{array}{c}0.00298^{* *} \\
(0.000877)\end{array}$ & $\begin{array}{c}0.00313^{* *} \\
(0.000652)\end{array}$ \\
\hline$\omega^{m}$ & $\begin{array}{c}0.172^{* *} \\
(0.00645)\end{array}$ & $\begin{array}{c}0.170^{* *} \\
(0.00216)\end{array}$ & $\begin{array}{c}0.221^{* *} \\
(0.00322)\end{array}$ & $\begin{array}{c}0.158^{* *} \\
(0.00400)\end{array}$ & $\begin{array}{c}0.161^{* *} \\
(0.00299)\end{array}$ \\
\hline$\omega^{s}$ & $\begin{array}{c}0.828^{* *} \\
(0.00638)\end{array}$ & $\begin{array}{c}0.830^{* *} \\
(0.00218)\end{array}$ & $\begin{array}{c}0.776^{* *} \\
(0.00349)\end{array}$ & $\begin{array}{c}0.839^{* *} \\
(0.00430)\end{array}$ & $\begin{array}{c}0.836^{* *} \\
(0.00314)\end{array}$ \\
\hline$\psi$ & $\begin{array}{l}0.826^{* *} \\
(0.0968)\end{array}$ & $\begin{array}{c}0.779^{* *} \\
(0.0420)\end{array}$ & $\begin{array}{c}0.560^{* *} \\
(0.00194)\end{array}$ & $\begin{array}{c}0.557^{* *} \\
(0.00178)\end{array}$ & $\begin{array}{c}0.557^{* *} \\
(0.00443)\end{array}$ \\
\hline$\gamma$ & $\begin{array}{l}0.267^{*} \\
(0.119)\end{array}$ & $\begin{array}{l}0.334^{* *} \\
(0.0719)\end{array}$ & $\begin{array}{l}5.717^{* *} \\
(0.315)\end{array}$ & $\begin{array}{l}6.922^{* *} \\
(0.341)\end{array}$ & $\begin{array}{l}6.850^{* *} \\
(0.515)\end{array}$ \\
\hline$N$ & 64 & 64 & 64 & 64 & 64 \\
\hline$A I C$ & -1209.4 & -1210.8 & -1244.1 & -1357.4 & -1359.4 \\
\hline$B I C$ & -1171.5 & -1166.6 & -1199.9 & -1306.9 & -1315.2 \\
\hline$R M S E^{a}$ & 0.004 & 0.004 & 0.004 & 0.004 & 0.004 \\
\hline$R M S E^{m}$ & 0.008 & 0.008 & 0.017 & 0.007 & 0.007 \\
\hline$R M S E^{s m}$ & 0.057 & 0.057 & 0.026 & 0.015 & 0.015 \\
\hline$R M S E^{s h}$ & 0.056 & 0.057 & 0.019 & 0.017 & 0.017 \\
\hline
\end{tabular}

Robust standard errors in parentheses

${ }^{\dagger} p<0.10,{ }^{*} p<0.05,{ }^{* *} p<0.01$

Note: $N$ stands for the number of the sample in the estimation. $A I C$ is Akaike Information Criterion. BIC is Bayesian Information Criterion. $R M S E^{j}$ is the Root Mean Squared Error for $j$-sector's share equation. 
Figure OA.4 - No Restriction on $\gamma$ : Model $1\left(\bar{c}^{s}=\bar{c}^{s h}=0\right)$ and Model $2\left(\bar{c}^{s h}=0\right)$
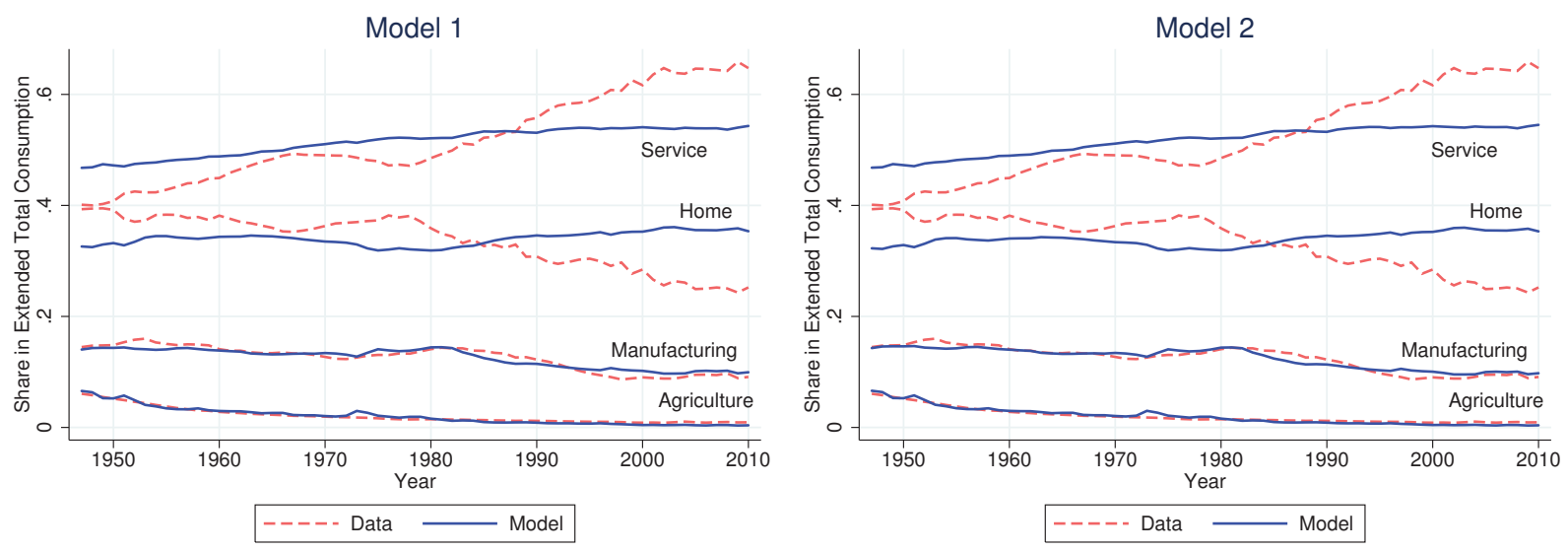

Figure OA.5 - No Restriction on $\gamma$ : Model $3\left(\bar{c}^{s}=0\right)$ and Model 4a (no restrictions)
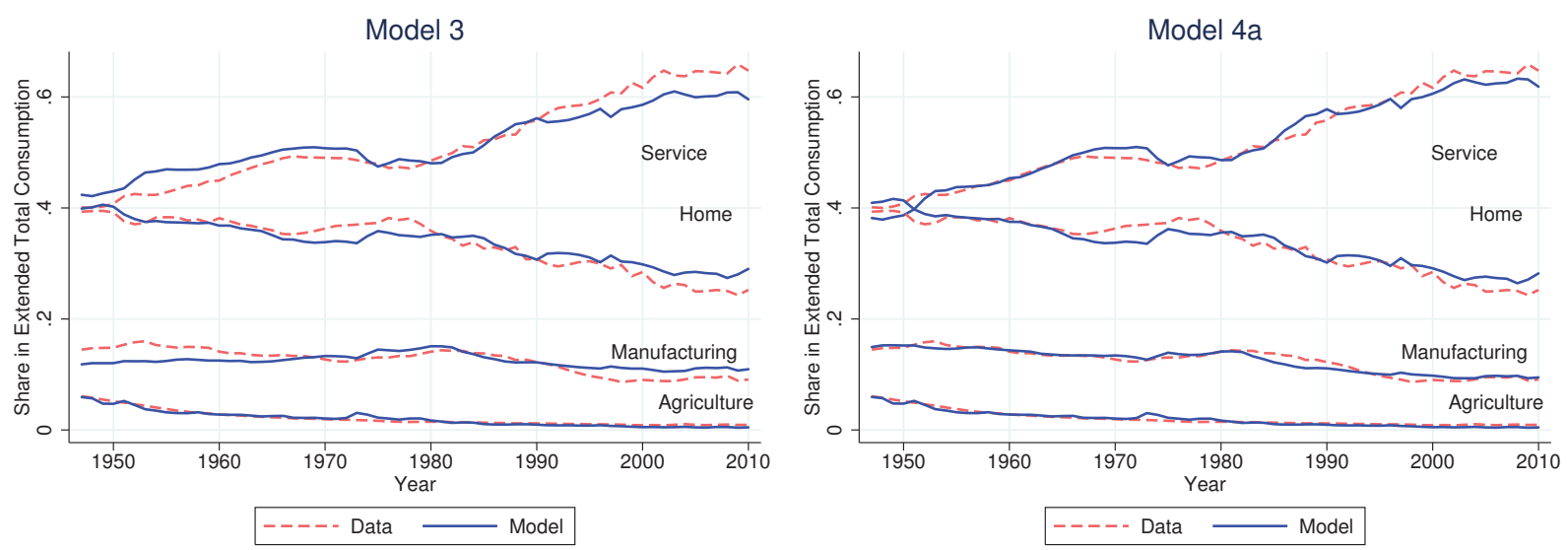

Figure OA.6 - No Restriction on $\gamma$ : Model 4b $(\sigma=0)$

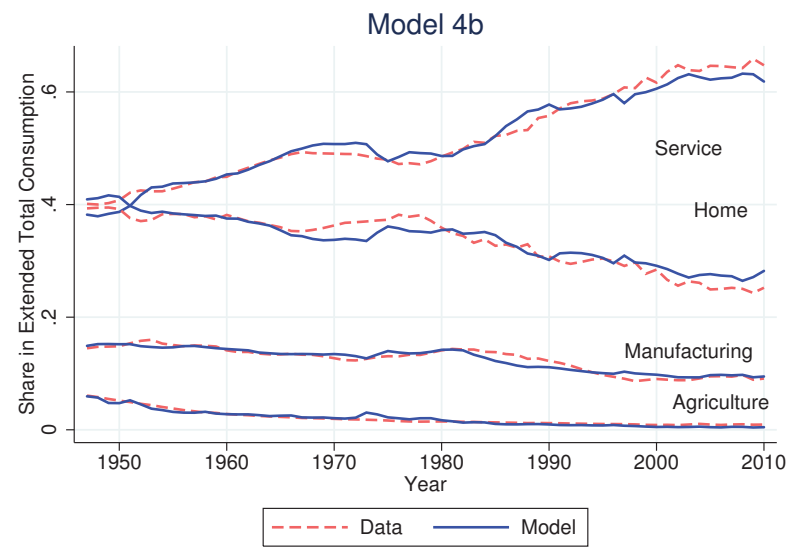




\section{Data Appendix for the Disaggregation of Services}

In order to create the consumption value added and the associated price data for the disaggregated case, we follow Herrendorf, Rogerson, and Valentinyi (2013). ${ }^{34}$ To apply their methodology to our disaggregated case, we need to make three adjustments to their original data set: 1) create expenditure on modern and traditional market services from final consumption expenditure data (discussed in Section 7.2); 2) create modern and traditional market service sectors in input-output matrices (discussed here); and 3) create the corresponding price data which have modern and traditional market service categories (discussed here).

\section{Input-Output Matrix}

In Herrendorf, Rogerson, and Valentinyi (2013), input-output matrices are based on the following seven sectors: Agriculture, Mining, Construction, Durable Manufacturing, Nondurable Manufacturing, Trade and Transport, and Services excluding Trade and Transport, indexed by $i \in\{A g, M i, C o, M a D, M a N, T T, S e\}$. They are aggregated to the three sectors as: $a=\{A g\}$, $m=\{M i, C o, M a D, M a N\}, s=\{T T, S e\}$. To make these data consistent with our model, we disaggregate Services excluding Trade and Transport sector into the following two parts: Modern Market Services $(S e N)$ and Traditional Market Services $(S e M)$. We then create input-output matrices based on the eight sectors indexed by $i \in\{A g, M i, C o, M a D, M a N, T T, S e N, S e M\}$ from BEA's Input-Output Table.

Table OA.3 shows how we disaggregate Services excluding Trade and Transport (Se) into Modern Market Services $(S e N)$ and Traditional Market Services $(S e M)$ in our input-output matrix for the year 2010. The classification of service categories in BEA's Input-Output Table is slightly different from the one in NIPA Table 2.4.5 of final consumption expenditure. Therefore, by using the information from the titles of service categories, we classify modern and traditional market services in our input-output matrices so that they are consistent with the definitions in the final consumption expenditure side. As a result, we consider "accommodation", "food services and drinking places", and "other services except government" as traditional market services, and the rest as the modern market services. ${ }^{35}$

From 1998 to 2010, the BEA's Input-Output Table is available for each year, and the consistent NAICS classification for products is used throughout the years. Therefore, we use the same definitions for modern and traditional market services as the one in Table OA.3. From 1947 to 1997, however, BEA's Input-Output Table is not available every year, and also the classification of goods and service categories differs by year. ${ }^{36}$ Therefore, whenever the BEA's Input-Output Table is available, we construct an input-output matrix with modern and traditional market service sectors based on the information from the service category titles in the data. ${ }^{37}$ Finally, from the inputoutput matrices, we create the so called total requirement matrices (TR matrices), and interpolate those to cover the missing years. A TR matrix directly links the income and the expenditure side

\footnotetext{
${ }^{34}$ For details of the methodology, please refer to their Online Appendix B.

${ }^{35}$ The category, other services except government (81), includes sub-categories: repair and maintenance (811), personal and laundry services (812), religious, grantmaking, civic, professional, and similar organizations (813), and private households (814).

${ }^{36}$ BEA's Input-Output Table is only available for the years, 1947, 1958, 1963, 1967, 1972, 1977, 1982 , 1987, 1992, 1997, and 1998 through 2010.

${ }^{37}$ The created input-output matrices with modern and traditional market service sectors are available upon request.
} 
of GDP, so it can be used to convert final consumption expenditure to consumption value added. ${ }^{38}$

TABle OA.3 - Modern and Traditional Services in the 2010 Input-Output Matrix

\begin{tabular}{ll}
\hline & Service Categories in the 2010 Input-Output Matrix \\
\hline Modern Market Services & Utilities (22), Publishing Industries (includes software) (511) \\
& Motion Picture and Sound Recording Industries (512) \\
& Broadcasting and Telecommunications (513) \\
& Information and Data Processing Services (514) \\
& Federal Reserve Banks, Credit Intermediation, and Related Activities (521CI) \\
& Securities, Commodity Contracts, and Investments (523) \\
& Insurance Carriers and Related Activities (524) \\
& Funds, Trusts, and Other Financial Vehicles (525), Real Estate (531) \\
& Rental and Leasing Services and Lessors of Intangible Assets (532RL) \\
& Legal Services (5411), Computer Systems Design and Related Services (5415) \\
& Miscellaneous Professional, Scientific, and Technical Services (5412OP) \\
& Management of Companies and Enterprises (55) \\
& Administrative and Support Services (561) \\
& Waste Management and Remediation Services (562), Educational Services (61) \\
& Ambulatory Health Care Services (621) \\
& Hospitals and Nursing and Residential Care Facilities (622HO) \\
& Social Assistance (624), Performing Arts, Spectator Sports, Museums (511AS) \\
& Amusements, Gambling, and Recreation Industries (713) \\
\hline Accommodation (721), Food Services and Drinking Places (722) \\
Other Services except Government (81) \\
\hline Traditional Market Services \\
\hline
\end{tabular}

Note: The numbers in brackets in the above table correspond to the NAICS codes.

\section{Prices}

To create prices for consumption value added, we use BEA's GDP-by-Industry Table. The data set allows us to look at industry level nominal value added, chain-weighted value-added quantities, and chain-weighted value-added prices. Since chain-weighted indices are not additive, we apply the so called cyclical expansion procedure to aggregate quantities into the four categories (agriculture, manufacturing, modern market services, and traditional market services) and then use them to calculate the aggregate prices for the four categories.

Table OA.4 reports how we aggregate industry-level price data into modern and traditional service sectors. Again, we divide all services into modern and traditional groups based on the information from their titles, so that the definitions are consistent with those in the consumption expenditure side. As a result, we choose "accommodation", "food services", and "other services except government" for traditional market services. We then apply the cyclical expansion procedure, and calculate aggregated quantity indices for the four sectors (agriculture, manufacturing, modern market services, and traditional market services). Once the quantity indices are obtained, it is straightforward to calculate the prices for the four sectors by using the nominal value added, aggregated for the four sectors.

\footnotetext{
${ }^{38}$ For details about a TR matrix, see the Online Appendix B in Herrendorf, Rogerson, and Valentinyi (2013).
} 
TABLE OA.4 - Modern and Traditional Services in BEA's GDP-by-Industry Table

\begin{tabular}{ll}
\hline & Service Categories in BEA's GDP-by-Industry Table \\
\hline Modern Market Services & Utilities \\
& Wholesale Trade \\
& Retail Trade \\
& Transportation and Warehousing \\
& Information \\
& Finance, Insurance, Real Estate, Rental, and Leasing \\
& Professional and Business Services \\
& Educational Services \\
& Health Care and Social Assistance \\
& Arts, Entertainment, and Recreation \\
& Accommodation \\
& Food Services \\
Traditional Market Services & Other Services except Government \\
\hline
\end{tabular}




\section{Structural Breaks in Home Labor Productivity}

In this appendix, we discuss the estimation of structural breaks in home labor productivity, which we use in the counter-factual experiment in Sections 6 and 7.4. We follow the standard approach developed by Bai and Perron $(1998,2003)$, which allows us to estimate multiple structural breaks in a linear model estimated by least squares. ${ }^{39}$

More specifically, we estimate the following home labor productivity process with $m$ breaks $(m+1$ regimes $)$ for the period 1947 to 2010 :

$$
\ln A_{t}^{* s h}-\ln A_{t-1}^{* s h}=\delta_{j}+u_{t}, \quad t=T_{j-1}+1, \ldots, T_{j}
$$

for $j=1, \ldots, m+1$. Our concern centers on the number of regime switches $(m)$, the date of regime switches $\left(T_{1}, \ldots, T_{m}\right)$, and how the mean growth rate of labor productivity varies $\left(\delta_{j}\right)$ across the different regimes. When applying the Bai and Perron $(1998,2003)$ method, we allow up to 5 breaks, and use a trimming $\epsilon=0.10$ (meaning that each regime has at least 10 observations). ${ }^{40}$ We also allow serial correlations in the error terms and different variance of the residuals across the regimes.

Table OA.5 reports the results. As for the number of breaks, first, we note that $\sup F_{T}(k)$ $(k=1, \ldots, 5)$ tests are all significant at $1 \%$ level. Here, $\sup F_{T}(k)$ is a test statistic of no structural break $(m=0)$ versus a fixed number of breaks $(m=k)$. Also, UDmax and WDmax are tests of no structural breaks versus an unknown number of breaks given some upper bound on the number of breaks (here, $M=5$ ), both of which are significant at $1 \%$ level. ${ }^{41}$ Therefore, we conclude that at least one break is present. Next, we note that the $\sup F_{T}(2 \mid 1)$ test is significant at $1 \%$ level, while the $\sup F_{T}(3 \mid 2)$ and the $\sup F_{T}(4 \mid 3)$ are not significant. The statistic, $\sup F_{T}(l+1 \mid l)$, tests $l$ breaks versus $l+1$ breaks. Therefore, given the values of $\sup F_{T}(k)$ and $\sup F_{T}(l+1 \mid l)$, the sequential procedure selects two breaks at $1 \%$ significance level. While the BIC and the LWZ information criteria select one and zero breaks, respectively, those information criteria are known to be downward biased. ${ }^{42}$

In conclusion, the estimation results indicate that, at $1 \%$ significance level, there is one break between 1953 and $1954\left(\hat{T}_{1}=16\right)$ and another break between 1978 and $1979\left(\hat{T}_{1}=31\right)$. The switches of regimes first increased the mean growth rate, from $1.1 \%$ to $3.7 \%$ between 1963 and 1964, then, a large drop from 3.7\% to -0.5\% occurred between 1978 and 1979 .

In our counter-factual experiment in Section 7.4, we focus on the break that occurred between 1978 and 1979. We do this for two reasons: first, the change in the growth rate of labor productivity after the 1978-79 break is the most dramatic in magnitude. (Before the break, the mean growth rate of labor productivity is $2.3 \%$ during the $1947-1978$ period, while it is $-0.5 \%$ during the 1979 2010 period.) And, second, the 1978-79 break has long lasting effects compared to the other. (The home labor productivity has stagnated for more than 30 years since the break.)

\footnotetext{
${ }^{39}$ For the general survey on the estimation of a structural break, see Hansen (2001).

${ }^{40}$ Parameter values are standard in this framework. See Bai and Perron (2003).

${ }^{41}$ The value of those two test statistics is exactly same because of our model's specification, where there is only one variable that changes its value across regimes. See Bai and Perron (1998) for the definition of the test statistics.

${ }^{42}$ See Bai and Perron (2003).
} 
TABLE OA.5 - Estimation Results: Structural Breaks in Home Labor Productivity Series

\begin{tabular}{|c|c|c|c|c|c|c|}
\hline \multicolumn{7}{|c|}{ Tests } \\
\hline $\sup F_{T}(1)$ & $\sup F_{T}(2)$ & $\sup F_{T}(3)$ & $\sup F_{T}(4)$ & $\sup F_{T}(5)$ & $U D \max$ & WDmax \\
\hline $13.22^{* *}$ & $10.75^{* *}$ & $13.72^{* *}$ & $10.46^{* *}$ & $8.80^{* *}$ & $13.72^{* *}$ & $13.72^{* *}$ \\
\hline $\sup F(2 \mid 1)$ & $\sup F(3 \mid 2)$ & $\sup F(4 \mid 3)$ & & & & \\
\hline $18.79^{* *}$ & 1.39 & 2.23 & & & & \\
\hline \multicolumn{7}{|c|}{ Number of Breaks Selected } \\
\hline Sequential $1 \%$ & Sequential $5 \%$ & LWZ & $\mathrm{BIC}$ & & & \\
\hline 2 & 2 & 0 & 1 & & & \\
\hline \multicolumn{7}{|c|}{ Estimates with One Break } \\
\hline$\hat{\delta}_{1}$ & $\hat{\delta}_{2}$ & & & $\hat{T}_{1}$ & & \\
\hline 0.0232 & -0.0051 & - & - & 31 & - & - \\
\hline$(0.0068)$ & $(0.0067)$ & & & $(14,41)$ & & \\
\hline \multicolumn{7}{|c|}{ Estimates with Two Breaks } \\
\hline$\hat{\delta}_{1}$ & $\hat{\delta}_{2}$ & $\hat{\delta}_{3}$ & & $\hat{T}_{1}$ & $\hat{T}_{2}$ & \\
\hline 0.0107 & 0.0366 & -0.0051 & - & 16 & 31 & - \\
\hline$(0.0093)$ & $(0.0096)$ & $(0.0066)$ & & $(11,21)$ & $(23,33)$ & \\
\hline
\end{tabular}

Note: $* p<0.05, * * p<0.01$. In parentheses are the standard errors (robust to serial correlation) for $\hat{\delta}_{i}$, and the $95 \%$ confidence intervals for $\hat{T}_{i}$. 